\title{
Effects of small-scale freestream turbulence on turbulent boundary layers with and without thermal convection
}

\section{$\operatorname{AUTHOR}(\mathrm{S})$ :}

Nagata, Kouji; Sakai, Yasuhiko; Komori, Satoru

\section{CITATION:}

Nagata, Kouji ... [et al]. Effects of small-scale freestream turbulence on turbulent boundary layers with and without thermal convection. PHYSICS OF FLUIDS 2011, 23(6): 06511.

\section{ISSUE DATE:}

2011-06

URL:

http://hdl.handle.net/2433/160669

\section{RIGHT:}

Copyright 2011 American Institute of Physics. This article may be downloaded for personal use only. Any other use requires prior permission of the author and the American Institute of Physics. The following article appeared in PHYSICS OF FLUIDS 23, 065111 (2011) and may be found at http://link.aip.org/link/?phf/23/065111 


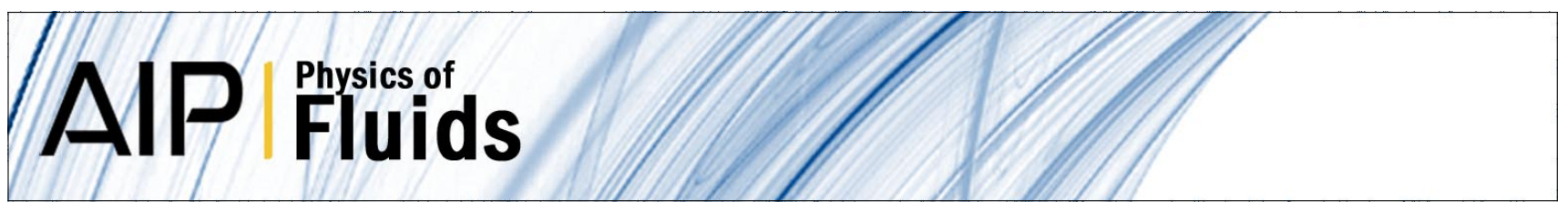

\section{Effects of small-scale freestream turbulence on turbulent boundary layers with and without thermal convection}

Kouji Nagata, Yasuhiko Sakai, and Satoru Komori

Citation: Phys. Fluids 23, 065111 (2011); doi: 10.1063/1.3596269

View online: http://dx.doi.org/10.1063/1.3596269

View Table of Contents: http://pof.aip.org/resource/1/PHFLE6/v23/i6

Published by the American Institute of Physics.

\section{Related Articles}

Asymptotic expansion of the solution of the steady Stokes equation with variable viscosity in a two-dimensional tube structure

J. Math. Phys. 53, 103702 (2012)

Large-eddy simulation of turbulent channel flow using explicit filtering and dynamic mixed models

Phys. Fluids 24, 085105 (2012)

Anisotropy in pair dispersion of inertial particles in turbulent channel flow

Phys. Fluids 24, 073305 (2012)

About turbulence statistics in the outer part of a boundary layer developing over two-dimensional surface roughness

Phys. Fluids 24, 075112 (2012)

Accounting for uncertainty in the analysis of overlap layer mean velocity models

Phys. Fluids 24, 075108 (2012)

\section{Additional information on Phys. Fluids}

Journal Homepage: http://pof.aip.org/

Journal Information: http://pof.aip.org/about/about_the_journal

Top downloads: http://pof.aip.org/features/most_downloaded

Information for Authors: http://pof.aip.org/authors

\section{ADVERTISEMENT}

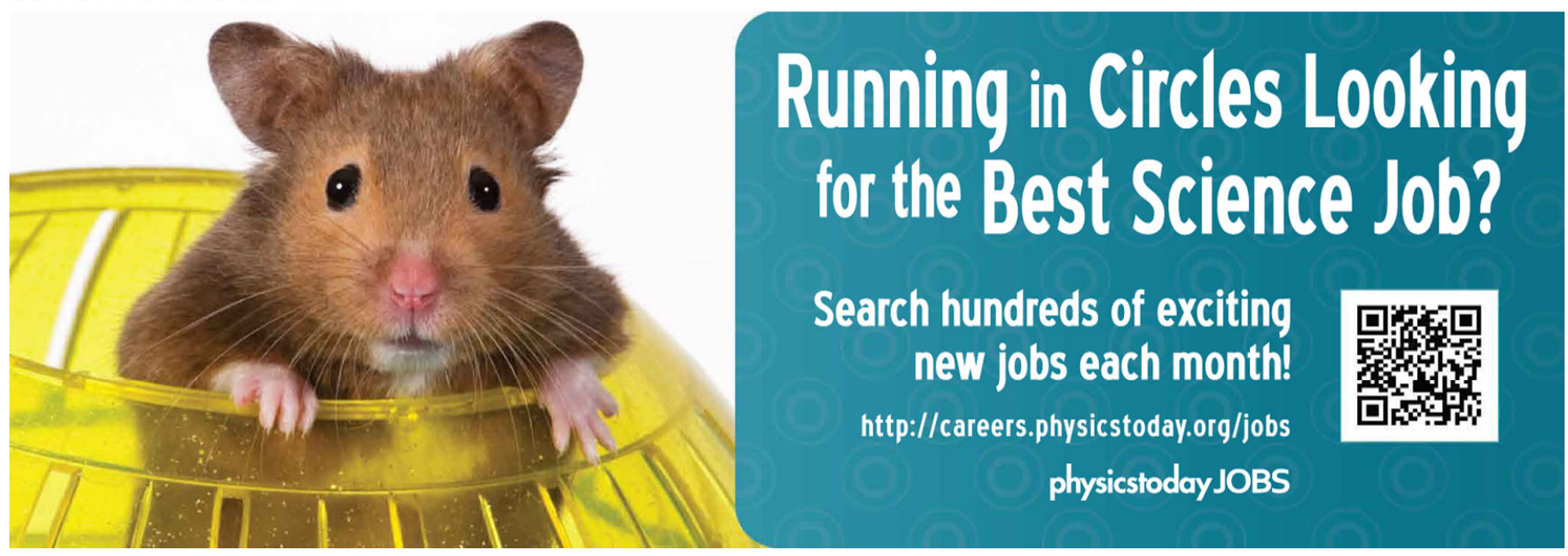




\title{
Effects of small-scale freestream turbulence on turbulent boundary layers with and without thermal convection
}

\author{
Kouji Nagata, ${ }^{1, a)}$ Yasuhiko Sakai, ${ }^{1}$ and Satoru Komori ${ }^{2}$ \\ ${ }^{1}$ Department of Mechanical Science and Engineering, Nagoya University, Nagoya 464-8603, Japan \\ ${ }^{2}$ Department of Mechanical Engineering and Science, and Advanced Research Institute of Fluid Science \\ and Engineering, Kyoto University, Kyoto 606-8501, Japan
}

(Received 21 October 2010; accepted 21 April 2011; published online 24 June 2011)

\begin{abstract}
Effects of weak, small-scale freestream turbulence on turbulent boundary layers with and without thermal convection are experimentally investigated using a wind tunnel. Two experiments are carried out: the first is isothermal boundary layers with and without grid turbulence, and the second is non-isothermal boundary layers with and without grid turbulence. Both boundary layers develop under a small favorable pressure gradient. For the latter case, the bottom wall of the test section is heated at a constant wall temperature to investigate the effects of thermal convection under the effects of freestream turbulence. For both cases, the turbulence intensity in the freestream is $T_{u}=1.3 \% \sim 2.4 \%$, and the integral length scale of freestream turbulence, $L_{\infty}$, is much smaller than the boundary layer thickness $\delta$, i.e., $L_{\infty} / \delta \ll 1$. The Reynolds numbers $\operatorname{Re}_{\theta}$ based on the momentum thickness and freestream speed $U_{\infty}$ are $R e_{\theta}=560,1100,1310$, and 2330 in isothermal boundary layers without grid turbulence. Instantaneous velocities, $U$ and $V$, and instantaneous temperature $T$ are simultaneously measured using a hot-wire anemometry and a constant-current resistance thermometer. The results show that the rms velocities and Reynolds shear stress normalized by the friction velocity are strongly suppressed by the freestream turbulence throughout the boundary layer in both isothermal and non-isothermal boundary layers. In the non-isothermal boundary layers, the normalized rms temperature and vertical turbulent heat flux are also strongly suppressed by the freestream turbulence. Turbulent momentum and heat transfer at the wall are enhanced by the freestream turbulence and the enhancement is notable in unstable stratification. The power spectra of $u, v$, and $\theta$ and their cospectra show that motions of almost all scales are suppressed by the freestream turbulence in both the isothermal and non-isothermal boundary layers. (C) 2011 American Institute of Physics. [doi:10.1063/1.3596269]
\end{abstract}

\section{INTRODUCTION}

In turbulent flows near rigid surfaces, a fluctuating velocity field is either locally generated by mean velocity gradients and body forces or transported there by the mean flow. For instance, in an atmosphere, turbulence is created above the surface layer by a shear-layer and/or by convective activity in deep clouds. ${ }^{1}$ In industrial flows such as those in turbomachines and heat exchangers, inflow streams often contain turbulent eddies generated by upstream structures. ${ }^{2-4}$ The effects of these freestream turbulence (FST) on a turbulent boundary layer (TBL) have been investigated in many researches. These researches include the wide area, for instance, the effects of freestream turbulence on laminar to turbulent transition, ${ }^{5}$ adverse-pressure-gradient turbulent boundary layer, ${ }^{6}$ separation bubble, ${ }^{7,8}$ separation and recovery behind a blunt horizontal or vertical plate, ${ }^{9-11}$ backward facing step flow, ${ }^{12}$ diffuser performance, ${ }^{3}$ the growth of a plane turbulent mixing layer, ${ }^{13}$ etc.

It has been shown, mainly by wind-tunnel experiments, that the skin friction in an isothermal turbulent boundary layer

\footnotetext{
${ }^{\text {a) }}$ Author to whom correspondence should be addressed. Electronic mail: nagata@nagoya-u.jp.
}

increases with increasing turbulence intensities in the freestream flow, ${ }^{14-19}$ and some empirical correlations between the enhancement of skin friction and turbulence parameters have been proposed. ${ }^{16,18,20,21}$ On the other hand, the effects of freestream turbulence on turbulence intensities and Reynolds shear stress (normalized by the friction velocity) in a turbulent boundary layer are controversial and need to be elucidated. Most of the previous experiments reveal an increase in turbulence intensities and Reynolds shear stress under the effect of freestream turbulence. 3,12,14,15,18,19,22 However, an interesting situation occurs when the integral length scale of freestream turbulence, $L_{\infty}$, is smaller than the boundary layer thickness $\delta$, i.e., $L_{\infty} / \delta<1$. Hancock and Bradshaw ${ }^{17}$ found that the freestream turbulence caused a significant decrease in turbulence intensities and Reynolds shear stress when $L_{\infty} / \delta<1$. However, on the other hand, Charnay et al. ${ }^{14}$ and Evans ${ }^{15}$ showed that the freestream turbulence caused an increase in turbulence intensities under the condition $L_{\infty} / \delta<1$. Note that in the study performed by Charnay et al. ${ }^{14}$ and Evans, ${ }^{15}$ the turbulence level in the freestream flow is not much higher than that in the turbulent boundary layer. In addition, no other data support the results of Hancock and Bradshaw for $L_{\infty} / \delta<1$. Thus, it is of importance to carry out additional experiments under the condition $L_{\infty} / \delta<1$. 
Effects of freestream turbulence on a turbulent boundary layer with forced convective heat transfer (i.e., the heat behaves as a passive scalar) have also been investigated. ${ }^{4,21,23-26}$ In most cases, with some exceptions, heat transfer at the wall (or Stanton number, St, or Nusselt number, $\mathrm{Nu}$ ) is found to increase with increasing turbulence level in a freestream flow, particularly for high-Reynolds-number flows. ${ }^{23,26}$ On the other hand, the effects of freestream turbulence on turbulent heat flux and temperature fluctuation in a turbulent boundary layer (away from the wall) are not well understood: few experimental data have been reported on turbulent heat flux and rms temperature in a boundary layer affected by the freestream turbulence. In addition, the previous studies on the effects of freestream turbulence on heat transfer were conducted in neutral or forced convective boundary layers, where the buoyancy force has negligible effects. It is expected that the effect of freestream turbulence may become significant in a non-isothermal boundary layer, where buoyancy-induced motions may weaken the coherent structure of wall turbulence. It is an open question whether the turbulent heat flux increases or decreases under the effects of freestream turbulence when $L_{\infty} / \delta<1$ and how buoyancy affects the flow, albeit the freestream turbulence will enhance the heat transfer at the wall. To the best of our knowledge, no experimental or numerical studies have been reported on the combined effects of freestream turbulence and buoyancy on turbulence characteristics in a turbulent boundary layer.

In this paper, the effects of freestream turbulence on turbulent quantities inside boundary layers with and without thermal convection are investigated in a wind tunnel under the condition $L_{\infty} / \delta \ll 1$. To generate quasi isotropic freestream turbulence, turbulence-generating grids are installed upstream of a turbulent boundary layer. The turbulence intensity in the freestream flow is $T_{u}=1.3 \% \sim 2.4 \%$. The Reynolds numbers $R e_{\theta}$ based on the momentum thickness and freestream speed $U_{\infty}$ are $R e_{\theta}=560,1100,1310$, and 2330 in isothermal boundary layers without grid turbulence. For the case of non-isothermal boundary layer, the bottom wall of the test section is heated so as to obtain a constant wall temperature, and thus negative vertical temperature gradient is formed above the bottom wall. Instantaneous velocities, $U$ and $V$, and instantaneous temperature $T$ are simultaneously measured using hot-wire anemometry with an X-probe and a constant-current resistance thermometer with an I-probe.

\section{EXPERIMENTS}

\section{A. Experimental apparatus and measuring system}

Experiments were performed using a wind tunnel in Kyoto University. The apparatus is the same as used in Kurose $e t a l .{ }^{27}$, with a glass test section of $5 \mathrm{~m}$ length $(x)$, $0.3 \mathrm{~m}$ height $(y)$, and $0.3 \mathrm{~m}$ width $(z)$. The heating apparatus on the flat bottom wall consists of an aluminium plate $\left(1 \times 10^{-3} \mathrm{~m}\right.$ thick), a specially-made silicon rubber heater $\left(3 \times 10^{-3} \mathrm{~m}\right.$ thick; OM Heater), and an insulator $\left(3 \times 10^{-3}\right.$ $\mathrm{m}$ thick). The wall temperature was monitored using a resistance thermometer, and was controlled using a proportional- integral-derivative (PID) control unit (OM Heater OT-3) so as to keep the wall temperature constant.

For the experiments with freestream turbulence, turbulence-generating grids were installed at the entrance to the test section. Two square-mesh and biplane grids, M50 and $M 25$, were used. $M 50$ was constructed from square-sectioned aluminium rods. For $M 50$, the mesh size $M$ and the rod thickness $d$ were $5 \times 10^{-2} \mathrm{~m}$ and $1 \times 10^{-2} \mathrm{~m}$, respectively, and therefore, its solidity was $\sigma=0.36$. This value of $\sigma$ is typical of the turbulence-generating grids used in the previous studies. $^{28-30} M 25$ was constructed from square-sectioned brass rods. For this grid, $M$ and $d$ were $2.5 \times 10^{-2} \mathrm{~m}$ and $5 \times 10^{-3}$ $\mathrm{m}$, respectively, and therefore, its solidity was $\sigma=0.36$.

Instantaneous streamwise and vertical velocities in a turbulent boundary layer were simultaneously measured using a standard constant-temperature hot-wire anemometer (DANTEC 55C16) with a miniature $\mathrm{X}$-probe with a $90^{\circ}$ array (DANTEC 55P61). The hot wires were $5 \times 10^{-6} \mathrm{~m}$ platinum-plated tungsten wires with a length-to-diameter ratio $l / d_{w}$ of 250 and a sensor separation of $1 \times 10^{-3} \mathrm{~m}$. For measurement in the non-isothermal boundary layer, instantaneous temperature was also measured simultaneously using a standard constant-current cold-wire anemometer (DANTEC $55 \mathrm{C} 16)$ equipped with an I-probe having offset prongs (DANTEC 55P05). The cold wire was a $5 \times 10^{-6} \mathrm{~m}$ goldplated tungsten wire. The total length of the wire was $3 \mathrm{~mm}$ and the length of the sensor was $1.25 \mathrm{~mm}\left(l / d_{w}=250\right)$. The power spectra of temperature fluctuations and the cospectra of the Reynolds shear stress and heat flux revealed that the main transport phenomena occurred in the range $f<10^{3} \mathrm{~Hz}$ in the present flows. Therefore, for the present flows, a $5 \times 10^{-6} \mathrm{~m}$ diameter wire was sufficient. The I-probe was located upstream of the X-probe with the small gap $\Delta l$. The effect of the I-probe on velocity measurement was carefully checked by changing $\Delta l$. When $\Delta l<1.5 \times 10^{-3} \mathrm{~m}$, the velocity field was contaminated by the wake of the I-probe. Therefore, the I-probe was mounted $1.7 \times 10^{-3} \mathrm{~m}(\Delta l /$ $\left.d_{w}=340\right)$ upstream of the X-probe. The gap $\Delta l$ was compensated by giving a time lag to the signals, assuming frozen turbulence. Combined measurements using X- and I-probes have also been made in the previous studies. ${ }^{30-32}$ They used thinner wires, but in their experiment, the cold wire is placed parallel to the X-probe. In this arrangement, compensation of the distance between the probes cannot be possible. Note that the temperature measurement using their arrangement of the wires could be contaminated by the thermal wakes from the X-probe ${ }^{33}$. The calibrations of X-and I-probes were carried out in a small, specially designed wind tunnel, over the full range of velocities and temperatures used in the present experiments. The velocities were calculated using a modified form of King's law with a temperature dependent coefficient ${ }^{34}$. The X-wire was also calibrated in yaw in the same small wind tunnel. A set of calibration data were obtained for both hot-wire sensors by varying the yaw angle $\alpha$ from $-60^{\circ}$ to $60^{\circ}$, while maintaining a constant velocity across the probe. Then the effective velocity $U_{\text {eff }}$ is calculated from $U_{\text {eff }}=U f(\alpha)=U\left(\cos ^{2} \alpha+k^{2} \sin ^{2} \alpha\right)^{1 / 2}$ according to Hinze. ${ }^{35}$ Here, $f(\alpha)$ is a yaw function and the unknown coefficient $k$ for each wire was determined by the yaw-angle calibration. It has 
TABLE I. Experimental conditions for isothermal turbulent boundary layer with and without freestream turbulence.

\begin{tabular}{|c|c|c|c|c|c|c|c|c|c|c|c|}
\hline & Symbol & $U_{\infty}[\mathrm{m} / \mathrm{s}]$ & Grid & $u_{\tau}[\mathrm{m} / \mathrm{s}]$ & $\delta[\mathrm{m}]$ & $L_{\infty}[\mathrm{m}]$ & $L_{\infty} / \delta$ & $T_{u}[\%]$ & $\operatorname{Re}_{M}\left[\times 10^{3}\right]$ & $\operatorname{Re}_{\lambda}[-]$ & $\operatorname{Re}_{\tau}[-]$ \\
\hline NG-1 & $\bigcirc$ & 1.0 & - & 0.049 & 0.110 & - & - & - & - & - & 344 \\
\hline NG-2 & $\triangle$ & 1.5 & - & 0.068 & 0.110 & - & - & - & - & - & 476 \\
\hline NG-3 & $\square$ & 2.0 & - & 0.089 & 0.105 & - & - & - & - & - & 615 \\
\hline NG-4 & $i s$ & 4.0 & - & 0.167 & 0.100 & - & - & - & - & - & 1110 \\
\hline LG-1 & ○ & 1.0 & M50 & 0.049 & 0.112 & 0.023 & 0.205 & 2.18 & 3.33 & 21 & 365 \\
\hline LG-2 & $\boldsymbol{\Delta}$ & 1.5 & M50 & 0.070 & 0.102 & 0.024 & 0.235 & 2.08 & 5.00 & 25 & 475 \\
\hline LG-3 & $\bar{\square}$ & 2.0 & M50 & 0.094 & 0.098 & 0.030 & 0.306 & 2.44 & 6.67 & 36 & 607 \\
\hline LG-4 & $\star$ & 4.0 & M50 & 0.174 & 0.092 & 0.034 & 0.370 & 2.44 & 13.3 & 55 & 1050 \\
\hline SG-1 & + & 1.0 & $M 25$ & 0.050 & 0.112 & 0.017 & 0.152 & 1.28 & 3.33 & 13 & 365 \\
\hline SG-2 & $\nabla$ & 1.5 & $M 25$ & 0.070 & 0.102 & 0.020 & 0.196 & 1.46 & 5.00 & 18 & 475 \\
\hline SG-3 & $\diamond$ & 2.0 & $M 25$ & 0.090 & 0.098 & 0.020 & 0.204 & 1.48 & 6.67 & 23 & 607 \\
\hline SG-4 & $x$ & 4.0 & $M 25$ & 0.174 & 0.092 & 0.018 & 0.196 & 1.32 & 13.3 & 27 & 1050 \\
\hline
\end{tabular}

been shown ${ }^{36}$ that the effective angles deviate from the measured actual angles at low wind speed, especially below about $1 \mathrm{~m} / \mathrm{s}$. Thus, effective angles corresponding to the measured mean velocities were used according to Snyder and Castro. ${ }^{36}$

The sampling interval and the sample size were $2.5 \times 10^{-4}$ s and $2.4 \times 10^{5}$, respectively, and they were sufficient to obtain reliable statistics. The output voltage signals were digitized and recorded on the hard disc using a data recorder with an A/D converter (Sony EX-UT10). The digitized data were statistically processed using a personal computer.

\section{B. Experimental conditions}

Measurements were performed at $x=2.75 \mathrm{~m}$ from the leading edge $(x=0)$, where a fully developed turbulent boundary layer was generated. Due to the constant cross-sectional area of the test section, there was a small favorable pressure gradient in the streamwise direction. The most appropriate parameter to measure the effect of the pressure gradient would be the acceleration parameter

$$
K=\frac{\nu}{U_{\infty}^{2}} \frac{d U_{\infty}}{d x},
$$

where $\nu$ is the kinematic viscosity. The values of $K$ are $1.01 \times 10^{-6}, 0.58 \times 10^{-6}, 0.38 \times 10^{-6}$, and $0.10 \times 10^{-6}$ for $U_{\infty}=1.0,1.5,2.0$, and $4.0 \mathrm{~m} / \mathrm{s}$ without the grid (i.e., Runs NG-1 $\sim$ NG-4), respectively. The values of $K$ indicate that the effect of pressure gradient is small in our experiment.
Note that a substantial deviation from the log-law occurs only for $K>1.6 \times 10^{-6}$ (Ref. 37 ).

The coordinate system is as follows: the $x$-axis is along the streamwise direction, the $y$-axis is in the vertical direction starting from the wall surface, and $z$-axis is in the spanwise direction with $z=0$ being the center of the channel. To generate a fully developed turbulent boundary layer in a short distance, the transition was promoted by using 10 small rods of $2 \times 10^{-3} \mathrm{~m}$ diameter placed on the bottom wall near the leading edge. The distance between the rods was $2 \times 10^{-2} \mathrm{~m}$. Tables I and II list the experimental conditions for isothermal and non-isothermal boundary layers, respectively. Here, $u_{\tau}$, the friction velocity; $\delta$, the boundary layer thickness; $T_{u}=u_{\infty}^{\prime} / U_{\infty}$, the turbulence intensity in the freestream; $R e_{M}=U_{\infty} M / \nu$, the mesh Reynolds number; $R e_{\lambda}=u_{\infty}^{\prime} \lambda_{\infty} / \nu$, the Taylor Reynolds number in the freestream $(\lambda$ is the Taylor microscale); and $R e_{\tau}=u_{\tau} \delta / \nu$, the boundary-layer Reynolds number. The suffix $\infty$ is used throughout to denote the values in the freestream. Freestream speeds of $U_{\infty}=1.0,1.5,2.0$, and $4.0 \mathrm{~m} / \mathrm{s}$ were chosen to investigate the buoyancy effects in a non-isothermal boundary layer and for the comparison between the non-isothermal and isothermal turbulent boundary layers. The Reynolds numbers $R e_{\theta}$ based on the momentum thickness $\theta$ and $U_{\infty}$ are $R e_{\theta}=560,1100,1310$ and 2330 for $U_{\infty}=1.0,1.5,2.0$, and $4.0 \mathrm{~m} / \mathrm{s}$ without the grid (i.e., Runs NG-1 NG-4), respectively. It should be noted that because of the small spanwise length of the test section relative to the boundary layer thickness, two-dimensionality is satisfied only in the central region of $-75 \mathrm{~mm}<z<75 \mathrm{~mm}$. However, as

TABLE II. Experimental conditions for non-isothermal boundary layer with and without freestream turbulence.

\begin{tabular}{|c|c|c|c|c|c|c|c|c|c|c|c|c|}
\hline & Symbol & $U_{\infty}[\mathrm{m} / \mathrm{s}]$ & Grid & $u_{\tau}[\mathrm{m} / \mathrm{s}]$ & $\delta[\mathrm{m}]$ & $L_{\infty}[\mathrm{m}]$ & $L_{\infty} / \delta$ & $T_{u}[\%]$ & $\operatorname{Re}_{M}\left[\times 10^{3}\right]$ & $\operatorname{Re}_{\lambda}[-]$ & $R e_{\tau}[-]$ & $R i_{b}[-]$ \\
\hline NG-cl & 0 & 1.0 & - & 0.055 & 0.150 & - & - & - & - & - & 549 & 0.323 \\
\hline NG-c2 & $\triangle$ & 1.5 & - & 0.071 & 0.120 & - & - & - & - & - & 567 & 0.115 \\
\hline NG-c3 & $\square$ & 2.0 & - & 0.089 & 0.115 & - & - & - & - & - & 674 & $6.19 \times 10^{-2}$ \\
\hline NG-c4 & $t^{2}$ & 4.0 & - & 0.167 & 0.100 & - & - & - & - & - & 1110 & $1.35 \times 10^{-2}$ \\
\hline LG-cl & 0 & 1.0 & M50 & 0.058 & 0.145 & 0.023 & 0.159 & 2.18 & 3.33 & 21 & 560 & 0.312 \\
\hline LG-c2 & $\Delta$ & 1.5 & $M 50$ & 0.078 & 0.095 & 0.024 & 0.253 & 2.08 & 5.00 & 25 & 493 & $9.09 \times 10^{-2}$ \\
\hline LG-c3 & $\mathbf{\square}$ & 2.0 & $M 50$ & 0.101 & 0.090 & 0.030 & 0.333 & 2.44 & 6.67 & 36 & 605 & $4.85 \times 10^{-2}$ \\
\hline LG-c4 & $\star$ & 4.0 & M50 & 0.177 & 0.100 & 0.034 & 0.340 & 2.44 & 1.33 & 55 & 1180 & $1.35 \times 10^{-2}$ \\
\hline
\end{tabular}




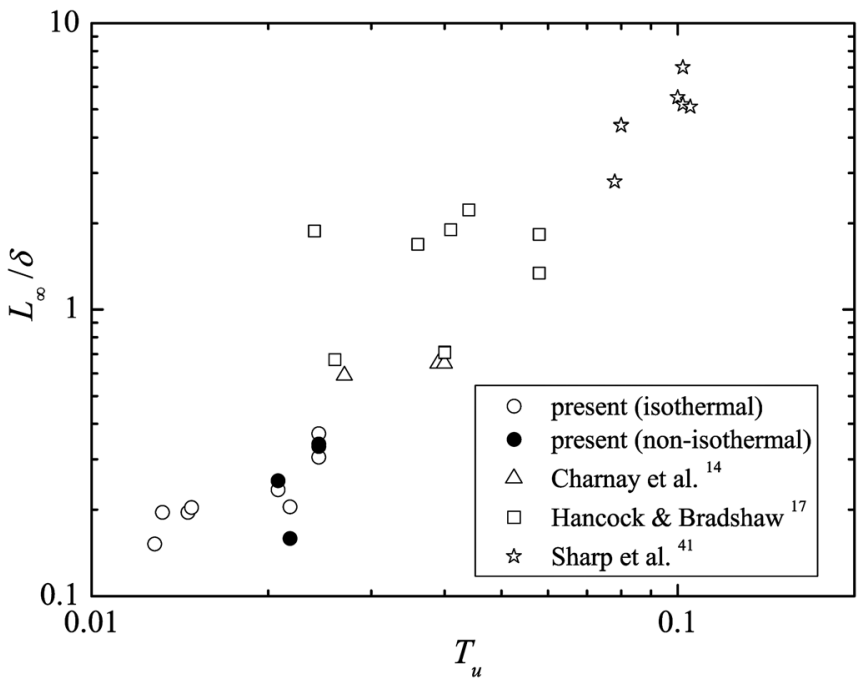

FIG. 1. $T_{u}$ versus $L_{\infty} / \delta$.

shown later, profiles of rms velocities and Reynolds shear stress measured at $z=0$ agree well with previous experiments $^{37}$ and direct numerical simulation (DNS). ${ }^{38,39}$ For the case of non-isothermal boundary layers, the temperature difference between the wall and freestream was set to $\Delta T=60 \mathrm{~K}$. The bulk Richardson number

$$
R i_{b}=\frac{\beta g \Delta T \delta}{U_{\infty}^{2}}
$$

is also listed in Table II. Here, $\beta$ is the thermal volumetric expansion coefficient and $g$ is the gravitational acceleration. In this paper, the values of $R i_{b}$ for the turbulent boundary layers without grid turbulence (i.e., Runs NG-cl $\sim \mathrm{c} 4$ ) are used to express the experimental conditions. To achieve thermal equilibrium of the apparatus and to make the flow field steady, the experiments were started after at least $2 \mathrm{~h}$ of warm-up for non-isothermal conditions. This warm-up reduced the thermal convection from the sidewall.

Figure 1 shows the relation between $T_{u}$ and $L_{\infty} / \delta$ in the present and previous experiments. Obviously, present experiments fill the blank in the previous experiments.

\section{RESULTS AND DISCUSSION}

\section{A. Effects of freestream turbulence on isothermal turbulent boundary layers}

In this section, the experimental results of turbulence quantities in the turbulent boundary layer under the effects of freestream turbulence generated by the grid $\left(L_{\infty} / \delta \ll 1\right.$ and $T_{u}=1.3 \% \sim 2.4 \%$ ) will be presented and discussed.

Figure 2 shows the vertical distributions of time-averaged velocity near the wall. The friction velocity $u_{\tau}$ is determined from the Clauser fits, since it has been shown that the log-law remains valid for determining wall shear stress for a turbulent boundary layer influenced by the freestream turbulence up to $T_{u}=20 \%{ }^{40,41}$ Here, only the results for M50 are shown, since the results for M25 were similar. We see that the development of the mean velocity

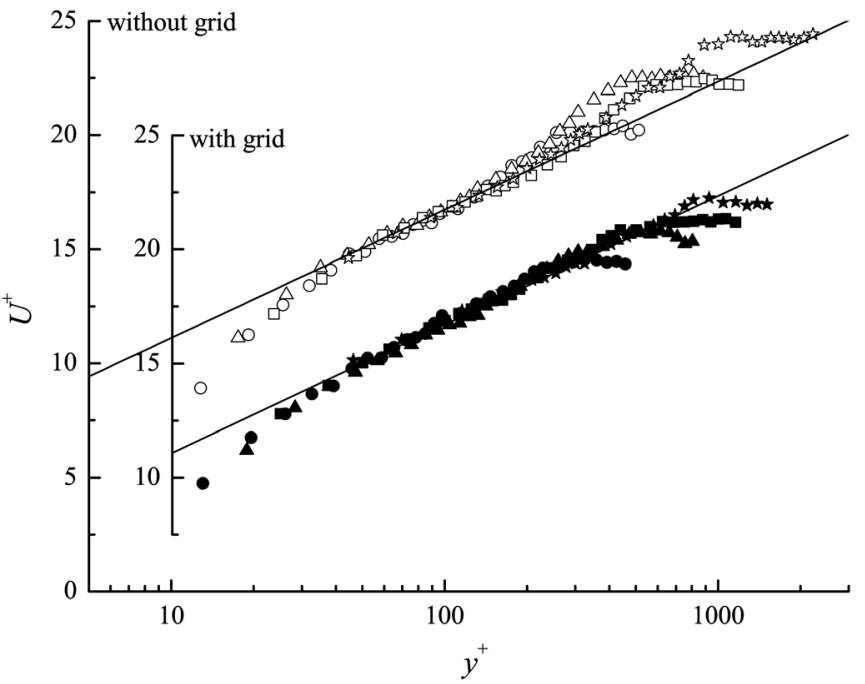

FIG. 2. Vertical distributions of time-averaged velocity. For symbols, see Table I.

field in the inner region of the turbulent boundary layer is insensitive to freestream turbulence and the profile is well fitted by the log-law profile

$$
U^{+}=\frac{1}{0.41} \log y^{+}+5.5 .
$$

On the other hand, the outer wake regions are strongly affected by the freestream turbulence. The results are consistent with previous studies. ${ }^{14-16,18,19,21,40,41}$ Note that the freestream turbulence strongly affects the mean or instantaneous reverse flow in a boundary layer with an adversedpressure-gradient. ${ }^{6}$

Figure 3 shows the vertical distributions of rms velocities near the wall at $R e_{\theta}=1100$ and 2330 . Here, the rms velocities are normalized by $u_{\tau}$. The previous experimental results for boundary layers with very small favorable pressure gradients ${ }^{37}$ and DNS results for boundary layers with a zero pressure gradient ${ }^{38,39}$ are also plotted for comparison. The present results for a pure boundary layer without grid turbulence agree well with the previous studies. The results suggest that the effect of favorable pressure gradient is small in this study as inferred from the values of the acceleration parameter. With grid turbulence, it is shown that normalized rms velocities are less influenced by the freestream turbulence in the vicinity of the wall. This implies that the freestream turbulence does not greatly alter the structure and turbulence-generation mechanism near the wall under the present condition of $L_{\infty} / \delta \ll 1$ and $T_{u}=1.3 \% \sim 2.4 \%$. On the other hand, rms velocities at $y^{+}>40$ are strongly suppressed by the freestream turbulence. The ratios of rms velocities under the effect of freestream turbulence to those without freestream turbulence, $u_{r m s}$ (with FST) $/ u_{r m s}$ (without FST) and $v_{r m s}$ (with FST) $/ v_{r m s}$ (without FST), are shown in Fig. 4. We observe that rms velocities are considerably suppressed by the freestream turbulence. Such suppression has been observed by Hancock and Bradshaw. ${ }^{17}$ However, in other previous experiments, ${ }^{12,14,15,18,19,22}$ turbulence intensities are increased by the freestream turbulence. Note that in the vicinity of the wall, both $u_{r m s}$ and $v_{r m s}$ (which are not 

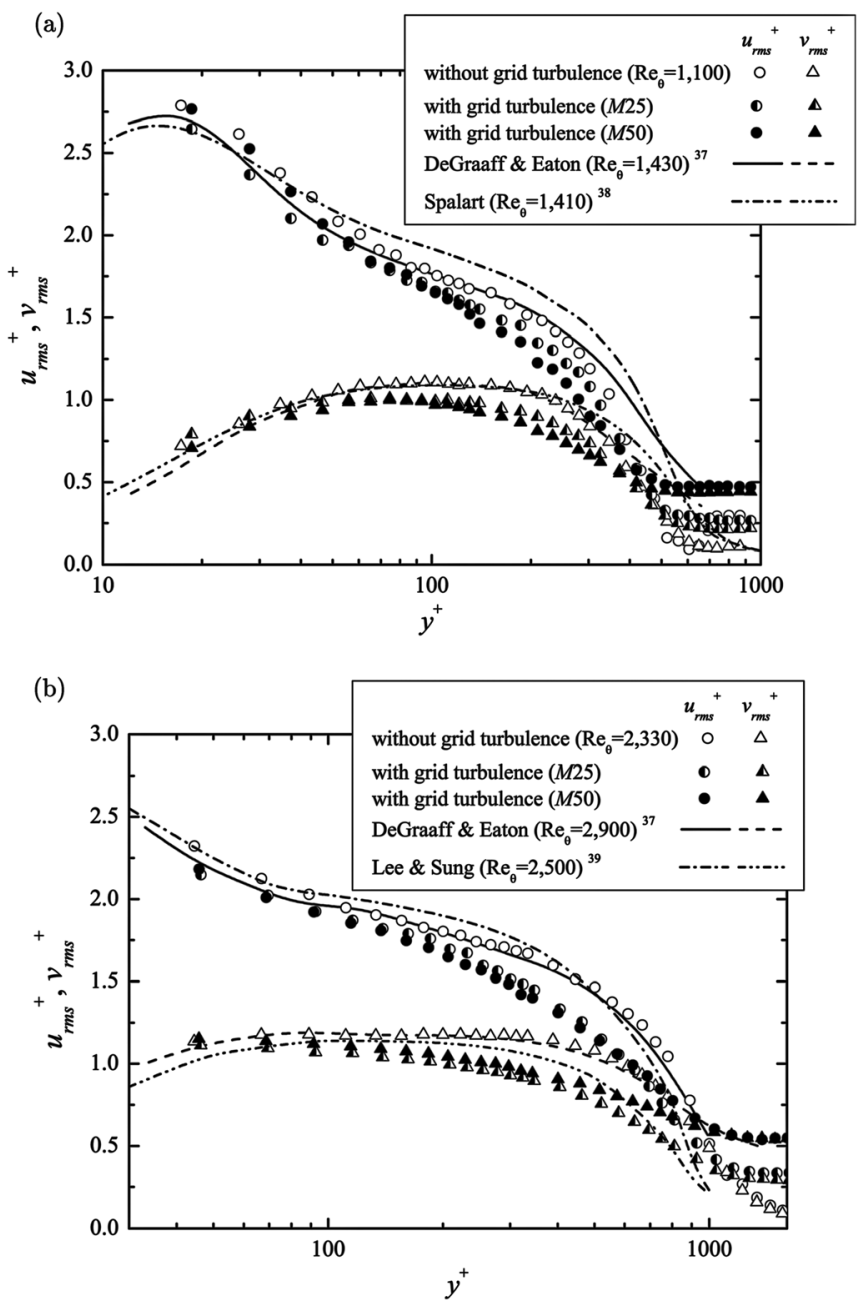

FIG. 3. Vertical distributions of rms velocities near the wall: (a) $R e_{\theta}=1100$ and (b) $R e_{\theta}=2330$.

normalized by $u_{\tau}$ ) increase under the effect of freestream turbulence. The increase is related to the increase in skin friction caused by the freestream turbulence, which has been observed in the previous studies. ${ }^{14-18}$ Note also that for the pure wall-blocking effect in a shear-free flow, streamwise

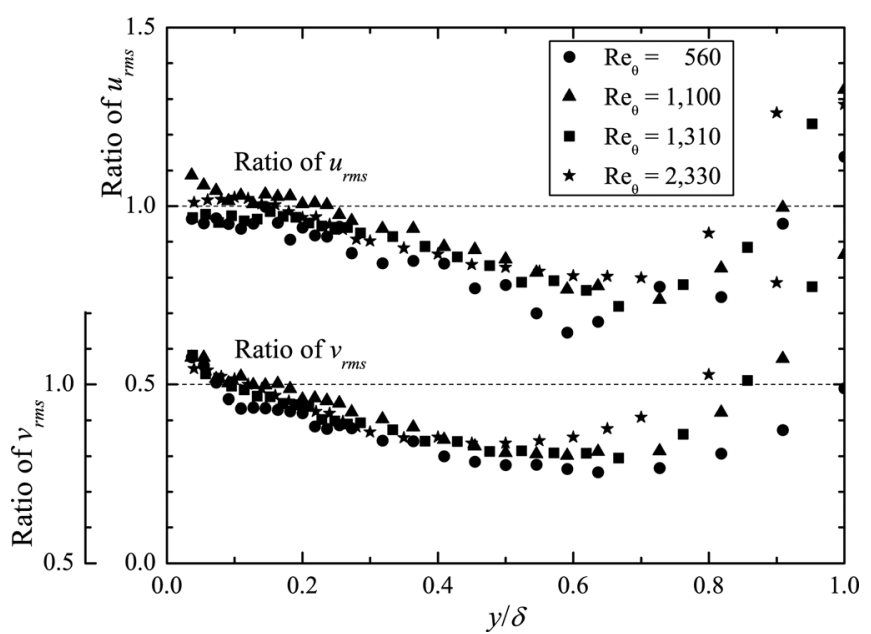

FIG. 4. Ratio of the rms velocities, $u_{r m s}$ (with FST) $/ u_{r m s}$ (without FST) and $v_{r m s}\left(\right.$ with FST) $/ v_{r m s}$ (without FST).

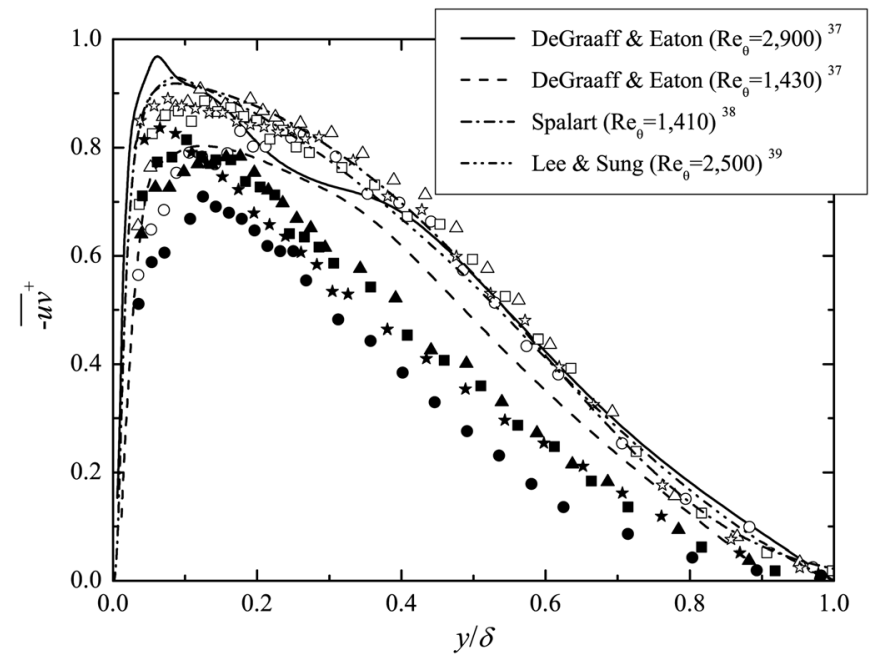

FIG. 5. Vertical distributions of the Reynolds shear stress near the wall. For symbols, see Table I.

turbulence intensity is amplified near a rigid surface, i.e., the splat effect occurs. ${ }^{42,43}$ This effect becomes predominant if the turbulence level in a freestream flow is more intense than that in a turbulent boundary layer, as shown by Hancock and Bradshaw. ${ }^{17}$

Figure 5 shows the vertical distributions of the Reynolds shear stress. The Reynolds shear stress is strongly suppressed throughout the boundary layer. This result is consistent with that reported by Hancock and Bradshaw, ${ }^{17}$ but inconsistent with other studies conducted using turbulence-generating grids ${ }^{14,15}$ and rods. ${ }^{19}$ Like the rms velocities, the Reynolds shear stress (which is not normalized by $u_{\tau}^{2}$ ) increases in the vicinity of the wall, as shown in Fig. 6 .

Here, we summarize previous studies in Table III. It should be noted that we pay attention to the changes in the profiles near the wall. Thus, even when the profile increases away from the wall, it is categorized as "reduction" if the value is reduced near the wall. Note also that when the freestream is turbulent, the profiles of rms velocities must cross the profiles without freestream turbulence if the value is reduced near the wall. Turbulence intensities and Reynolds

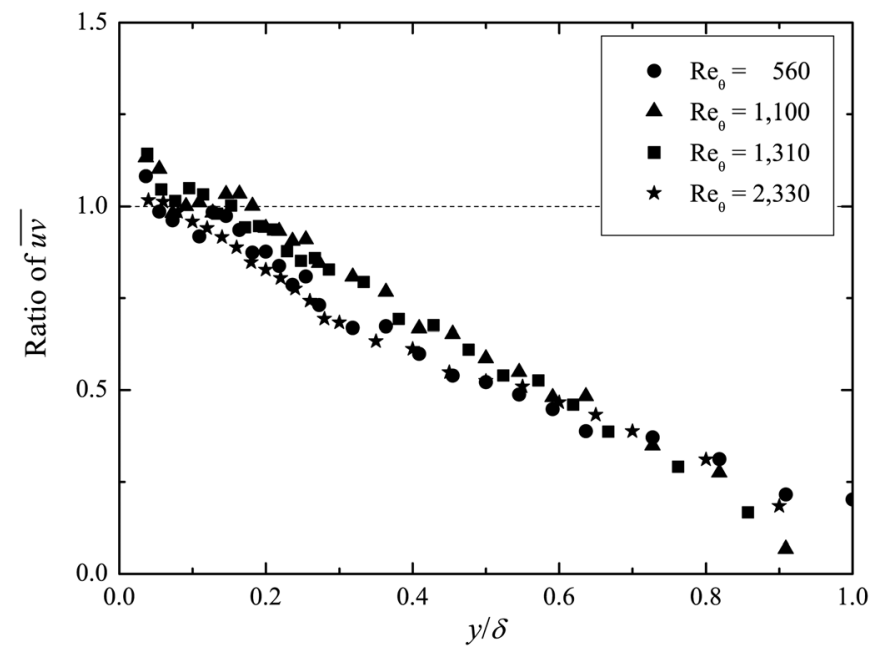

FIG. 6. Vertical distributions of the ratio of Reynolds shear stress, $\overline{u v}$ (with FST) $/ \overline{u v}$ (without FST). 
TABLE III. Comparisons of experiments. $\uparrow:$ increase; $\downarrow$ : decrease near the wall; and $\rightarrow$ : no significant effect. $k^{+}=\frac{u_{r m s}^{+2}+2.2 v_{r m s}^{+2}}{2}$. FPG: favorable pressure gradient, ZPG: zero pressure gradient.

\begin{tabular}{|c|c|c|c|c|c|c|c|c|c|}
\hline & $M[\mathrm{~mm}]$ & $\delta[\mathrm{mm}]$ & $L_{\infty} / \delta$ & $M / \delta$ & $T_{u}[\%]$ & $u_{r m s}^{+}$ & $v_{r m s}^{+}$ & $w_{r m s}^{+}$ & $-\overline{u v}^{+}$ \\
\hline \multirow[t]{2}{*}{ Present study (FPG) } & 50 & $92 \sim 112$ & $0.21 \sim 0.37$ & $0.45 \sim 0.54$ & $2.1 \sim 2.4$ & $\downarrow$ & $\downarrow$ & - & $\downarrow$ \\
\hline & 25 & $92 \sim 112$ & $0.15 \sim 0.20$ & $0.23 \sim 0.27$ & $1.3 \sim 1.5$ & $\downarrow$ & $\downarrow$ & - & $\downarrow$ \\
\hline Charnay et al. (Ref. 14) (ZPG) & 56 & 30 & $0.58 \sim 0.66$ & 1.9 & $2.6 \sim 4.7$ & $\uparrow$ & - & - & $\uparrow$ \\
\hline \multirow[t]{2}{*}{ Evans (Ref. 15) (ZPG) } & 12.7 & 28.7 & N/A & 0.44 & 3.4 & $\uparrow$ & $\uparrow$ & - & $\uparrow$ \\
\hline & 6.35 & 26.7 & N/A & 0.24 & 1.9 & $\uparrow$ & $\uparrow$ & - & $\uparrow$ \\
\hline Castro (Ref. 18) (ZPG) & 50,100 & N/A & $0.8 \sim 2.9$ & N/A & $2.3 \sim 7$ & $\uparrow$ & - & - & - \\
\hline \multirow{6}{*}{$\begin{array}{l}\text { Hancock and Bradshaw } \\
\text { (Ref. 17) (ZPG) }\end{array}$} & 152 & 56.8 & 1.90 & 2.68 & 4.1 & $\uparrow$ & $\downarrow$ & $\uparrow$ & $\downarrow$ \\
\hline & 152 & 48.1 & 1.83 & 3.16 & 5.8 & $\uparrow$ & $\downarrow$ & $\uparrow$ & $\downarrow$ \\
\hline & 152 & 66.0 & 1.34 & 2.30 & 5.8 & $\uparrow$ & $\downarrow$ & $\uparrow$ & $\downarrow$ \\
\hline & 76 & 29.1 & 1.88 & 2.61 & 2.4 & $\rightarrow$ & $\rightarrow$ & $\rightarrow$ & $\rightarrow$ \\
\hline & 76 & 56.9 & 0.71 & 1.33 & 4.0 & $\downarrow$ & $\downarrow$ & $\downarrow$ & $\downarrow$ \\
\hline & 76 & 78.4 & 0.67 & 0.97 & 2.6 & $\downarrow$ & $\downarrow$ & - & $\downarrow$ \\
\hline \multirow[t]{3}{*}{$\begin{array}{l}\text { Sharp et al. (Ref. 41) } \\
\text { (FPG) }\end{array}$} & $\begin{array}{l}114 \text { (passive } \\
\text { grid) }\end{array}$ & 73.1 & 4.4 & 1.56 & 8.0 & $\uparrow$ & $\downarrow$ & - & $\downarrow$ \\
\hline & 114 (active grid) & 80.9 & 5.2 & 1.41 & 10.2 & $\uparrow$ & $\uparrow$ & - & $\uparrow$ \\
\hline & $\begin{array}{l}\text { Turbulence } \\
\text { promoter }\end{array}$ & $\delta[\mathrm{mm}]$ & $L_{\infty} / \delta$ & $T_{u}[\%]$ & $u_{r m s}^{+}$ & \multicolumn{2}{|r|}{$v_{r m s}^{+}$} & $w_{r m s}^{+}$ & $-\overline{u v}^{+}$ \\
\hline \multirow{3}{*}{$\begin{array}{l}\text { Kline et al. (Ref. 22) (ZPG) } \\
\text { Huffman et al. (Ref. 19) } \\
\text { (ZPG) }\end{array}$} & rods & 17 (no rod) & N/A & 5.7 & $\uparrow$ & \multicolumn{2}{|r|}{-} & - & - \\
\hline & $1 / 4$ in. rods & $16.9 \sim 19.2$ & N/A & $2.9 \sim 3.4$ & \multirow{2}{*}{$\begin{array}{l}\uparrow\left(k^{+}\right) \\
\uparrow\left(k^{+}\right)\end{array}$} & \multicolumn{2}{|r|}{-} & - & $\uparrow$ \\
\hline & $3 / 4$ in. rods & $23.7 \sim 25.1$ & N/A & $4.8 \sim 5.7$ & & & - & - & $\uparrow$ \\
\hline \multirow{3}{*}{$\begin{array}{l}\text { Hoffmann (Ref. 3) } \\
\text { Isomoto and Honami (Ref. 12) }\end{array}$} & rods & N/A & N/A & $1.6 \sim 2.1$ & $\uparrow$ & \multicolumn{2}{|r|}{-} & - & - \\
\hline & slot & N/A & N/A & $3.3,5.3$ & \multirow{2}{*}{$\begin{array}{l}\uparrow \\
\uparrow\end{array}$} & \multicolumn{2}{|r|}{-} & - & - \\
\hline & mesh & N/A & N/A & $5.7,7.4$ & & \multicolumn{2}{|r|}{-} & - & - \\
\hline
\end{tabular}

shear stress in an inner layer increase under the effect of freestream turbulence generated by grids, ${ }^{14,15,41}$ an upstream rod, ${ }^{3,19}$ and by slots and rectangular meshes. ${ }^{12}$ Castro and Epik $^{44}$ also observed an increase in turbulence intensities in the downstream of the separation region behind a blunt plate.

On the other hand, Hancock and Bradshaw ${ }^{17}$ found that the freestream turbulence caused a significant decrease in turbulence intensities and Reynolds shear stress when $L_{\infty} / \delta<1$. They claimed that both $T_{u}$ and length-scale ratio $L_{\infty} / \delta$ are important to determine the increase/decrease in turbulent intensities. In our experiments, $L_{\infty} / \delta \ll 1$, and the results are consistent with those of Hancock and Bradshaw. ${ }^{17}$ However, in a study conducted by Charnay et al., ${ }^{14}$ both the turbulence intensity $u_{r m s}^{+}$and the Reynolds shear stress increased despite a small length-scale ratio and a similar value of $T_{u}$. Further, in a study conducted by Evans, ${ }^{15}$ in which $L_{\infty} / \delta<1$ would be expected from the grid mesh size $M, u_{r m s}^{+}$and Reynolds shear stress were observed to increase. Recently, Sharp et al. ${ }^{41}$ showed that for low $T_{u}$ and large length-scale ratio of $L_{\infty} /$ $\delta=4.4, u_{r m s}^{+}$increases, while vertical rms velocity $v_{r m s}^{+}$and Reynolds shear stress decrease. They also show that at large $T_{u}$ and $L_{\infty} / \delta, u_{r m s}^{+}, v_{r m s}^{+}$, and Reynolds shear stress increase. Note that the Reynolds shear stress decreased even when $L_{\infty} /$ $\delta>1$ in Hancock and Bradshaw. ${ }^{17}$ These results suggest that the change in turbulence intensities and Reynolds shear stress may strongly depend on the turbulence level in a freestream and the length-scale ratio, but they are not the only parameters to lead to changes. Charnay et al. ${ }^{14}$ suggested that an aniso- tropic external turbulence, mainly a nonzero $-\rho \overline{u v}$, can also become a relevant parameter of the problem. It should be noted that for an anisotropic freestream turbulence, no previous data show the reduction of turbulence intensity and Reynolds shear stress. We will discuss this effect later.

To further investigate the effects of freestream turbulence on near-wall turbulence, probability density functions (PDFs), power spectra, and cospectra are calculated. Figures 7 and 8 show the PDFs of $u$ and $v$ at several vertical $(y)$ locations. These figures show that the PDFs do not vary significantly with the freestream turbulence. However, the quantitative comparison reveals that the negative tail of $u$-PDF and the positive tail of $v$-PDF deviate more than those in the turbulent boundary layer without freestream turbulence. These results are consistent with previous study for large $T_{u}$ and $L_{\infty} / \delta .^{41}$

Figure 9 shows the premultiplied one-dimensional power spectra of $u$ and $v$. The spectra are normalized by the turbulence intensities. Note that the abscissa is shown in log-scale and the ordinate is in linear-scale, so that the area bounded by the power spectra multiplied by the frequency $f$ corresponds to the normalized turbulence intensities. The measuring point is $y=0.05 \mathrm{~m}$, which corresponds to $y^{+} \sim 230$ and $y / \delta \sim 0.45$ for $R e_{\theta}=1100$ and to $y^{+} \sim 570$ and $y / \delta \sim 0.5$ for $R e_{\theta}=2330$, and where $u_{r m s}^{+}, v_{r m s}^{+}$, and Reynolds shear stress exhibit large reductions. Figure 9 shows that the normalized power spectra are not influenced by the freestream turbulence, even at the inner layer where turbulence intensities are strongly 
(a)

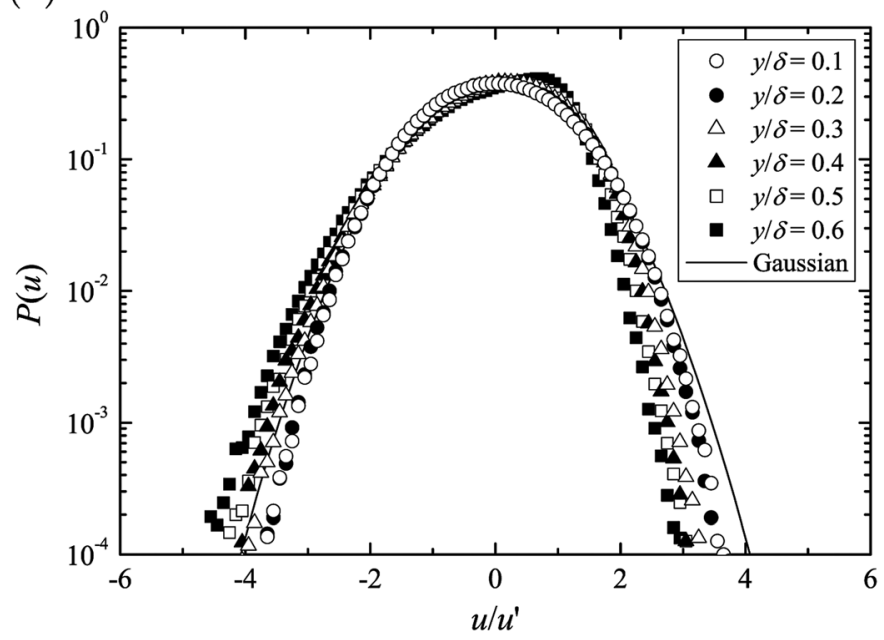

(b)

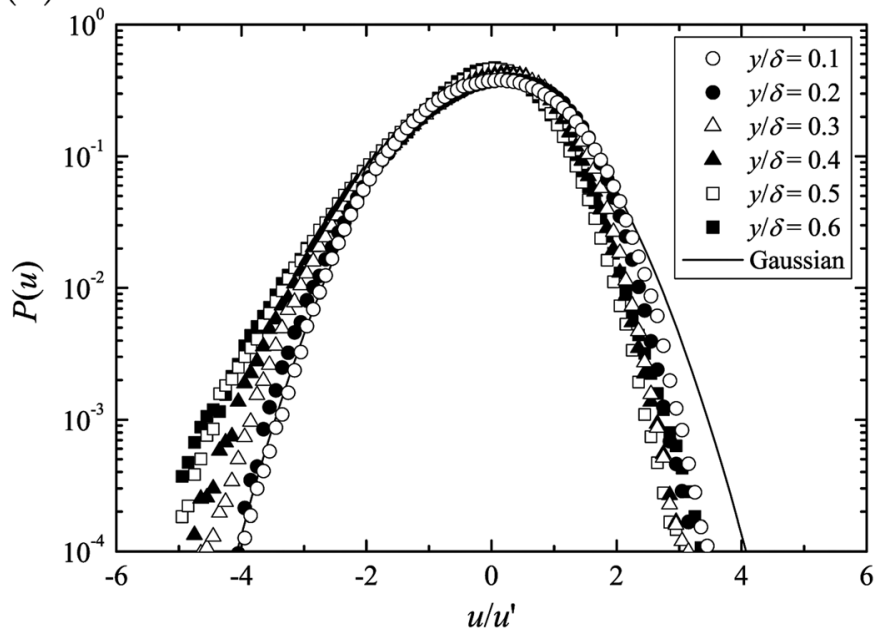

FIG. 7. PDF of $u$ at $R e_{\theta}=2330$ : (a) without grid turbulence and (b) with grid turbulence (M50).

suppressed. The result shows that eddy structures are not significantly destroyed by the freestream turbulence at the present low $T_{u}$ and small $L_{\infty} / \delta$. Note that for large $T_{u}$ and $L_{\infty} / \delta$, another peak associated with freestream grid turbulence appears in the power spectra. ${ }^{41}$

Figures 10 and 11 show the joint probability density functions of $u$ and $v$ at $R e_{\theta}=2330$ measured at $y / \delta=0.1$ and $y / \delta=0.5$, respectively. In all figures, contour interval is $0.012(0.24 /(20$ divisions $))$. Near the wall at $y / \delta=0.1$, we do not see the clear effect of freestream turbulence, as shown in Fig. 10. However, at $y / \delta=0.5$, Fig. 11 clearly shows that the strong negative correlation between $u$ and $v$ is weakened by the freestream turbulence. The weak correlation is consistent with a reduction in the Reynolds shear stress.

Figure 12 shows the premultiplied cospectra of $u$ and $v$

$$
-\overline{u v}=\int_{0}^{\infty} C s_{u v}(f) d f .
$$

The cospectra are normalized by the Reynolds shear stress, $-\overline{u v}$. The measuring point is the same as that in Fig. 9.

(a)

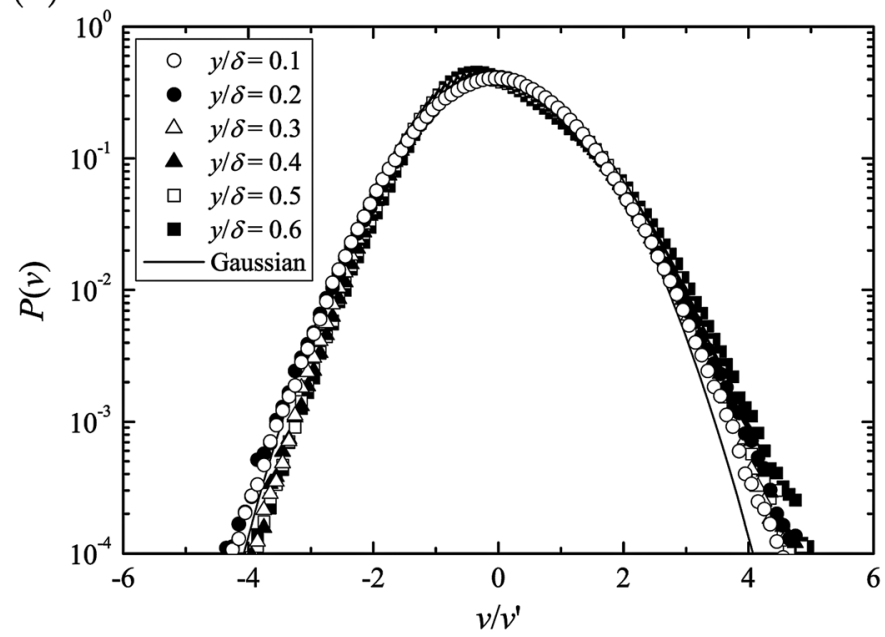

Figure 12 shows that the normalized cospectra are not greatly influenced by the freestream turbulence as for the normalized power spectra of $u$ and $v$ (Fig. 9).

Figure 13 shows the production terms for $\overline{u^{2}}$ and $\overline{u v}, P_{u u}$, and $P_{u v}$, respectively,

$$
P_{u u}=-2 \overline{u v} \frac{\partial \bar{U}}{\partial y}, \quad P_{u v}=\overline{v^{2}} \frac{\partial \bar{U}}{\partial y}
$$

at $R e_{\theta}=2330$. It is seen that the production terms decrease when the freestream is turbulent. This result is consistent with that obtained by Hancock and Bradshaw. ${ }^{17}$ Note that in both cases, $\partial \bar{U} / \partial y$ hardly changes throughout the boundary layer except the region very close to the wall (typically $y^{+}<50$ ).

Here, it is worth mentioning the previously reported effects of the low $R e_{\theta}$. Blair ${ }^{21}$ corrected the Hancock's parameter $^{16}$ for changes in skin friction coefficient by a factor of $\beta=1+3 \exp \left(-\operatorname{Re}_{\theta} / 400\right)$ to include the low Reynolds number effect. The modified parameter has also been applied to the heat transfer at the wall. Castro ${ }^{18}$ farther proposed a modified form of Hancock's parameter: it also contains the damping factor of $\exp \left(-R e_{\theta} / 400\right)$ to include the low Reynolds number

(b)

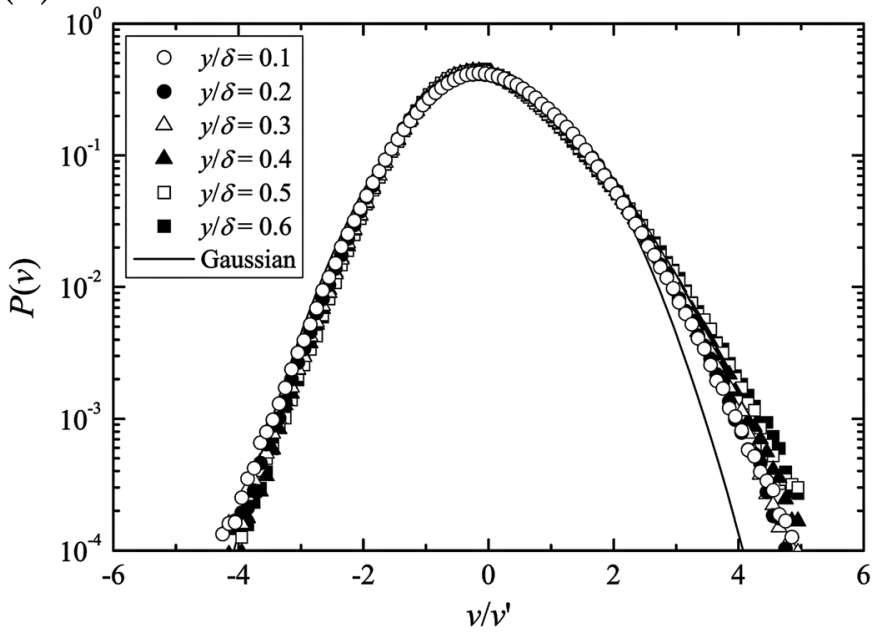

FIG. 8. PDF of $v$ at $R e_{\theta}=2330$ : (a) without grid turbulence and (b) with grid turbulence (M50). 
(a)
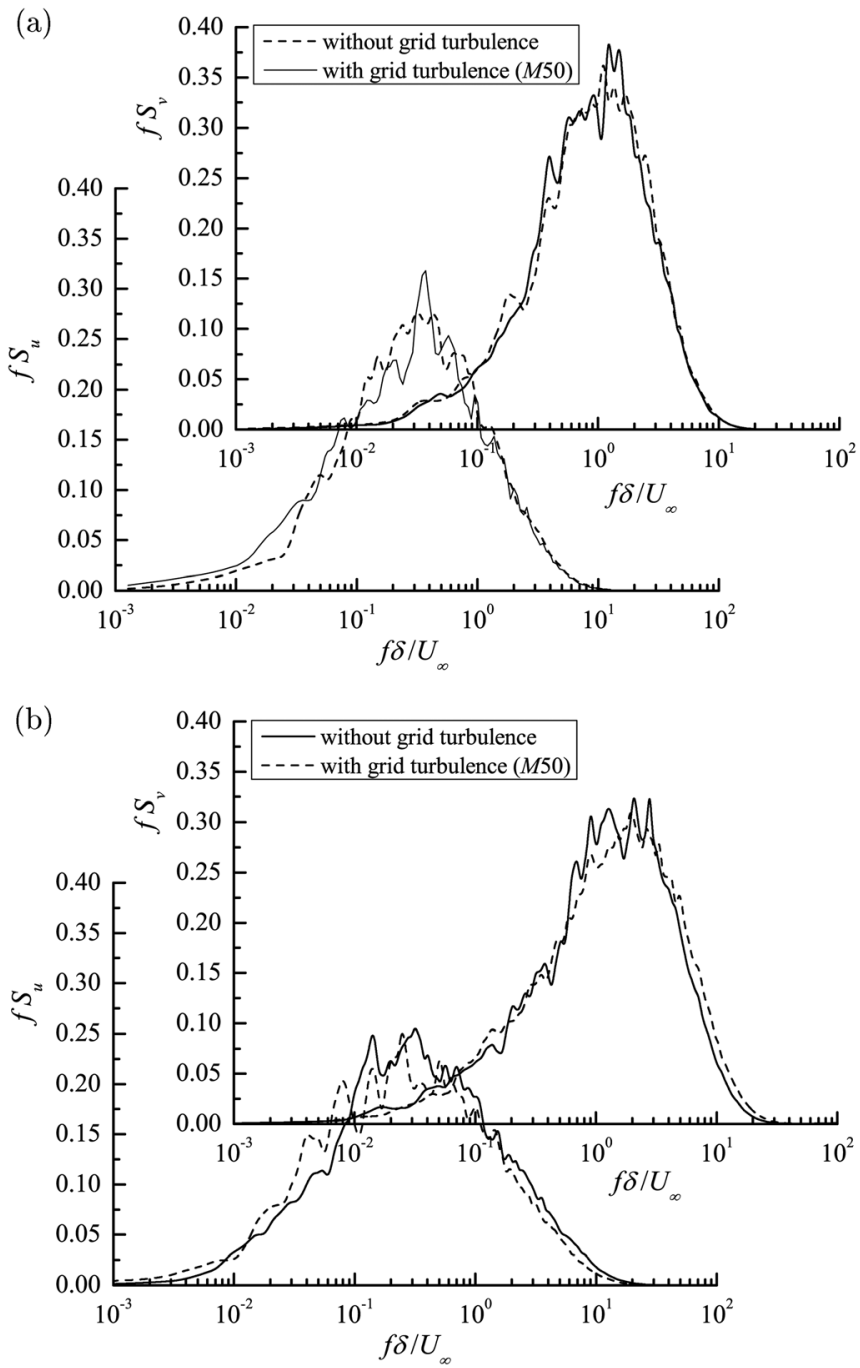

FIG. 9. Premultiplied power spectra of $u$ and $v$ : (a) $R e_{\theta}=1100$ and (b) $R e_{\theta}=2330$

effect. In our conditions, $\beta=1.74,1.19,1.11$, and 1.01 for $R e_{\theta}=560,1100,1310$, and 2330, respectively. Although the effects of buoyancy co-exist in our experiments, the effect of low Reynolds number may be significant only for $R e_{\theta}=560$ case. Note that the profile of the ratio of Reynolds shear stress (Fig. 6) do not vary significantly even for $R e_{\theta}=560$, despite the fact that the profiles of Reynolds shear stress (without grid turbulence) strongly depend on $R e_{\theta}$.

\section{B. Effects of freestream turbulence on non-isothermal boundary layers}

Figure 14 shows the vertical distributions of time-averaged velocity in the non-isothermal boundary layers. For weak convection $\left(R i_{b}=1.35 \times 10^{-2}\right)$, the log-law profile holds in an inner region and the profile of the wake region is affected by the freestream turbulence, as in the isothermal turbulent boundary layer. For strong convection $\left(R i_{b}=0.323\right)$, the mean profile deviates from the log-law profile, and the mean velocity profile becomes more flat, i.e., the vertical velocity gradient becomes small throughout the boundary layer (except the region very close to the wall). This is a typical profile for a strong convective boundary layer. Even for a strong convective boundary layer $\left(R i_{b}=0.323\right)$, the mean velocity profile is found to be insensitive to the freestream turbulence. The vertical distributions of time-averaged temperature $T\left(=\left(\bar{T}-T_{\infty}\right) / \Delta T\right)$ in the non-isothermal boundary layers are shown for reference in Fig. 15, where $T_{\infty}$ is the mean temperature in the freestream. Figure 15 confirms the formation of a non-isothermal boundary layer with a negative temperature gradient in the vertical direction. Note that $T$ should be 1.0 at the wall. However, because of steep temperature gradient near the wall, the normalized temperature drops to about 0.5 at the first measuring position.

Figure 16 shows the vertical distributions of rms velocities near the wall at $R i_{b}=0.115$ and $1.35 \times 10^{-2}$. Here, the rms velocities are normalized by the friction velocity $u_{\tau}$. The profiles for the isothermal condition (same as in Fig. 3) are also plotted for comparison. Without grid turbulence, $v_{r m s}^{+}$is more enhanced than $u_{r m s}^{+}$in the strong unstable condition $\left(R i_{b}=0.115\right)$ due to the buoyancy force. The result agrees qualitatively with previous DNS. ${ }^{45}$ In the weak unstable condition $\left(R i_{b}=1.35 \times 10^{-2}\right), u_{r m s}^{+}$and $v_{r m s}^{+}$are enhanced near the wall rather than away from the wall. Now, we turn our attention to the effects of freestream turbulence. Near the
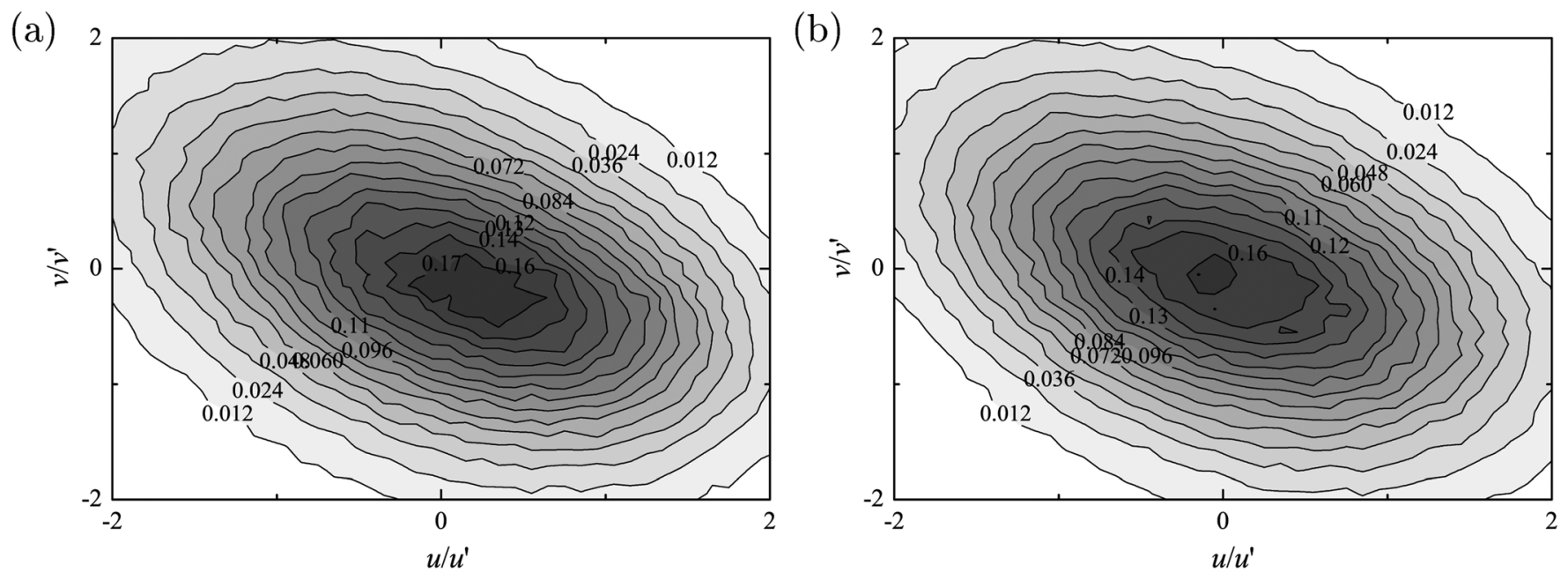

FIG. 10. Joint PDF of $u$ and $v$ at $y / \delta=0.1$ : (a) without grid turbulence and (b) with grid turbulence (M50). 
(a)

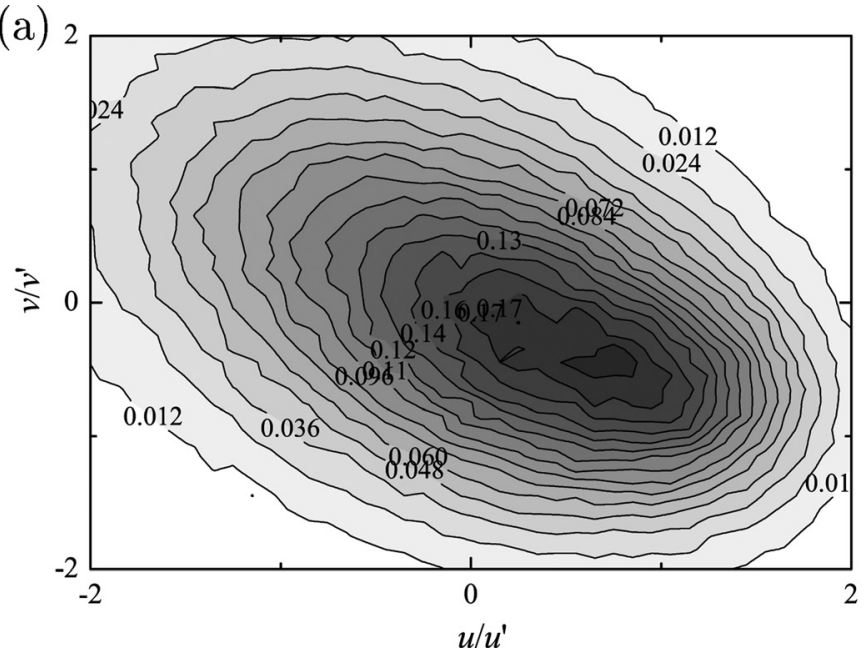

(b)

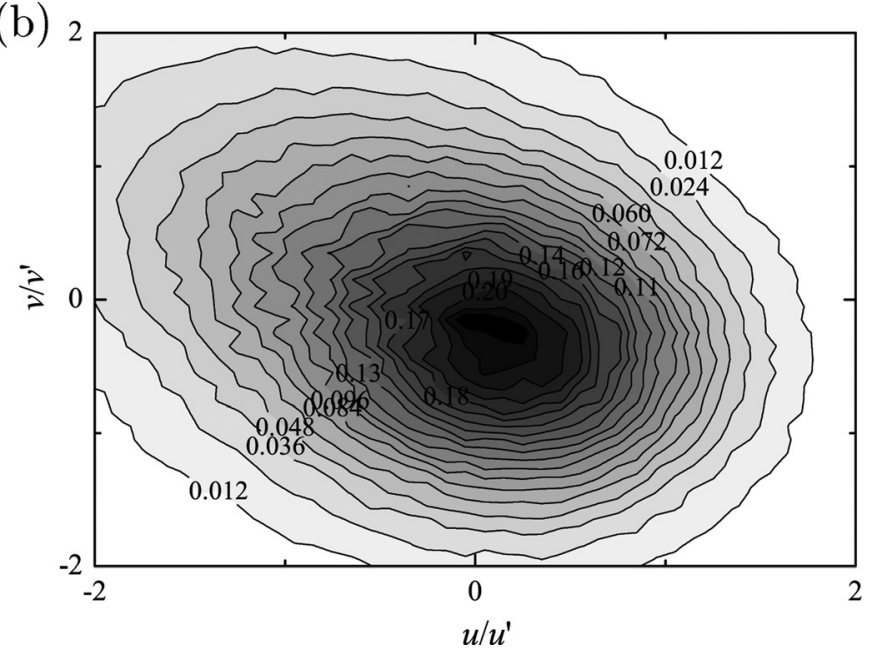

FIG. 11. Joint PDF of $u$ and $v$ at $y / \delta=0.5$ : (a) without grid turbulence and (b) with grid turbulence (M50).

wall, the normalized rms velocities are not influenced by the freestream turbulence, as in the isothermal case. However, the rms velocities are strongly suppressed by the freestream turbulence at $y^{+}>40$. These results are qualitatively the same as in the isothermal case, but the reduction is more significant in the unstable case than in the isothermal case.

Figure 17 shows the vertical distributions of rms temperature near the wall at $R i_{b}=0.115$ and $1.35 \times 10^{-2}$. Here, the rms temperatures are normalized by the friction temperature $\theta_{\tau}\left(=\left.\overline{v \theta}\right|_{\text {wall }} / u_{\tau}\right)$. In non-isothermal boundary layers, the change in normalized rms temperature by the freestream turbulence is small in the inner layer of the boundary layer. On the other hand, the rms temperatures are suppressed by the freestream turbulence in the outer layer of the boundary layer.

Figure 18 shows the reduction-ratios of rms velocities and rms temperature. At $R i_{b}=0.323$, the reductions in $u_{r m s}$ and $v_{r m s}$ are smaller than those in the isothermal case. These results suggest that energetic convective motions weaken the effect of the freestream turbulence. Here, the ratios of vertical (wall-normal) rms velocity in unstable condition to that in isothermal condition are $1.86,1.48,1.22$, and 1.17 for $R i_{b}$ $=0.323,0.115,6.19 \times 10^{-2}$, and $1.35 \times 10^{-2}$, respectively:

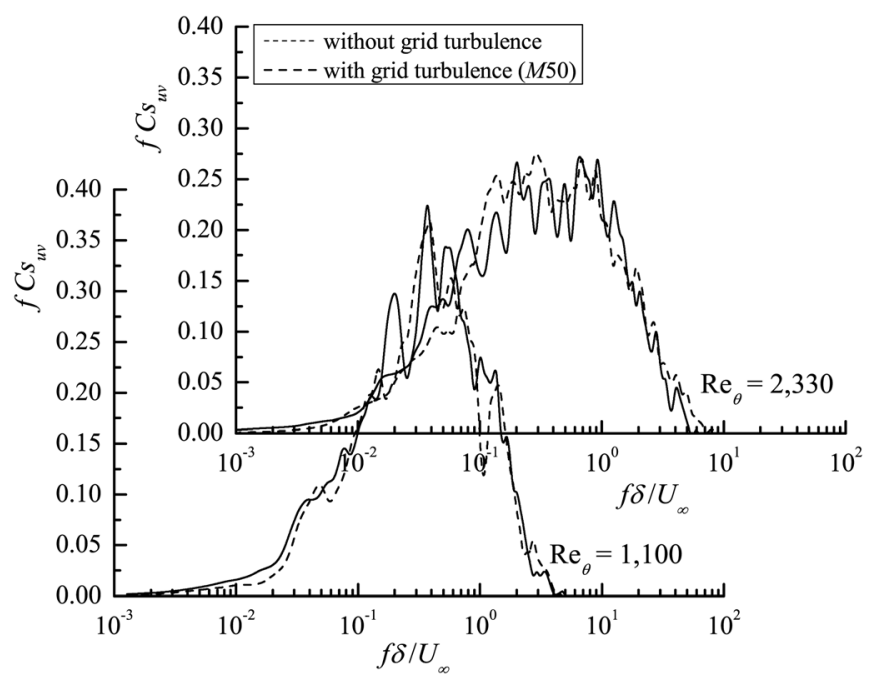

FIG. 12. Premultiplied cospectra of $u$ and $v$. energetic convective motions are supposed for $R i_{b}=0.323$. The reductions are most significant in the moderate stratification at $R i_{b}=6.19 \times 10^{-2}$. At the higher Reynolds number (or smaller $R i_{b}$ ) at $R i_{b}=1.35 \times 10^{-2}$, the effect of freestream turbulence becomes less significant again. Thus, the effect of
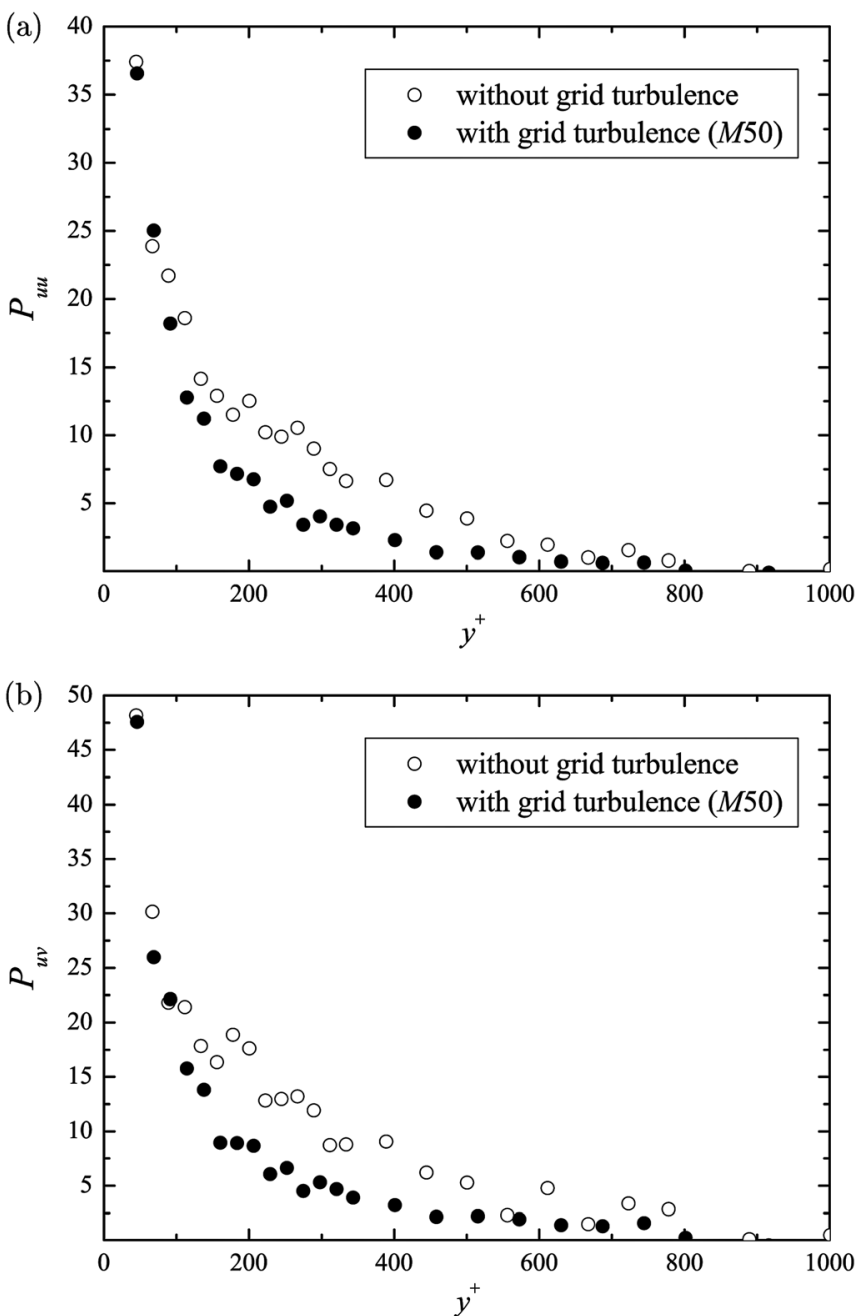

FIG. 13. Vertical distributions of the production terms at $R e_{\theta}=2330$ : (a) for $\overline{u^{2}}$ and (b) for $\overline{u v}$. 


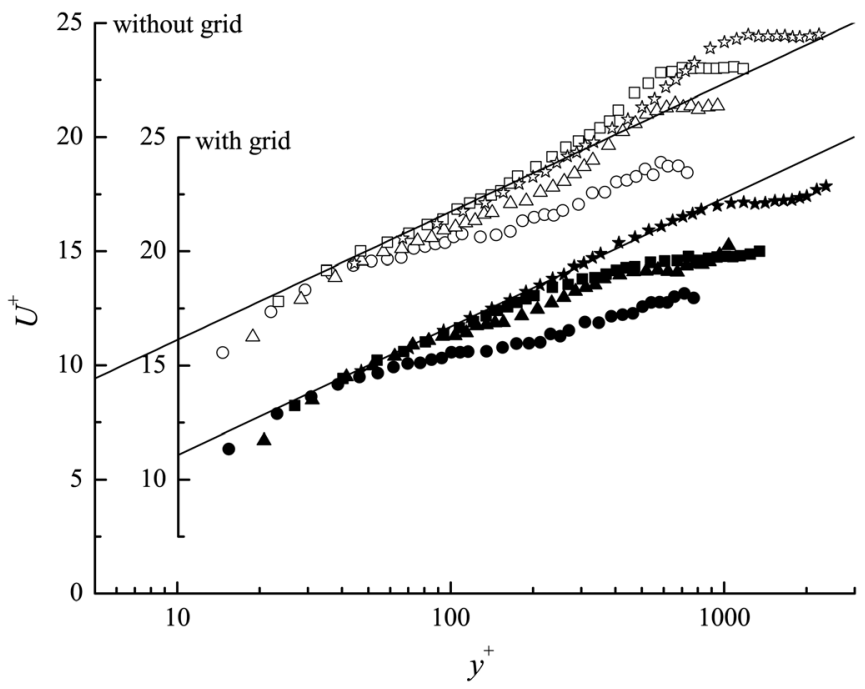

FIG. 14. Vertical distributions of time-averaged velocity. For symbols, see Table II.

the freestream turbulence on rms velocities depends on the strength of buoyancy. Like rms velocities, the reduction in the rms temperature is the most significant in the moderate stratification at $R i_{b}=6.19 \times 10^{-2}$. At the higher Reynolds number (or smaller $R i_{b}$ ) at $R i_{b}=1.35 \times 10^{-2}$, the effect of the freestream turbulence becomes less significant again.

Figure 19 shows the vertical distributions of the normalized Reynolds shear stress. The Reynolds shear stress is strongly suppressed throughout the boundary layer, except for $R i_{b}=0.323$ in which strong convective motions weaken the effect of the freestream turbulence. Figure 20 shows the vertical distributions of the vertical turbulent heat flux, normalized by $u_{\tau}$ and $\theta_{\tau}$. The vertical turbulent heat flux is also suppressed throughout the boundary layer except the region very close to the wall. It should be noted that no previous experiments have shown a reduction in the rms temperature and vertical turbulent heat flux under the effect of freestream turbulence. Figures 21 and 22 show the reduction-ratio of the Reynolds shear stress and the vertical turbulent heat flux, respectively. In the vicinity of the wall, we can notice an increase in the turbulent heat flux as well as Reynolds shear

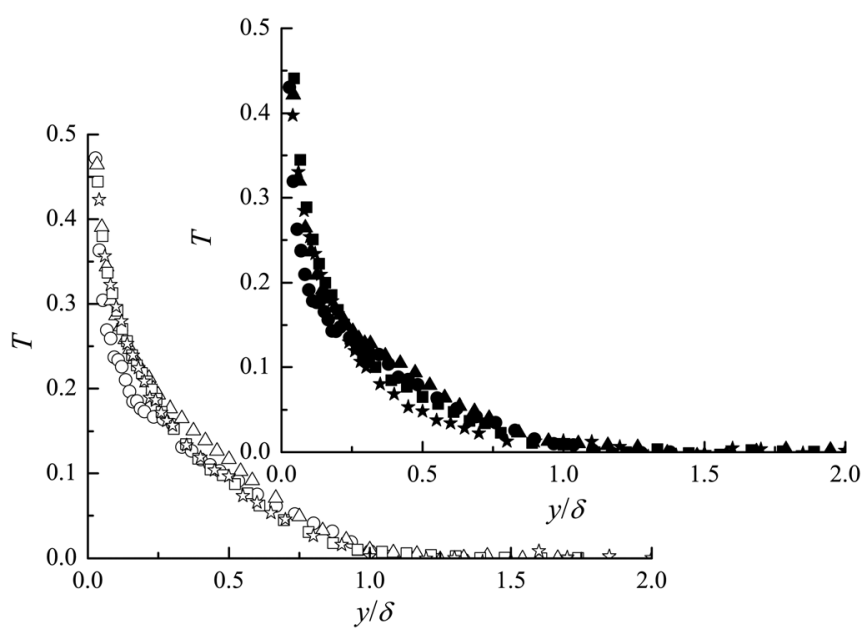

FIG. 15. Vertical distributions of time-averaged temperature. For symbols, see Table II.
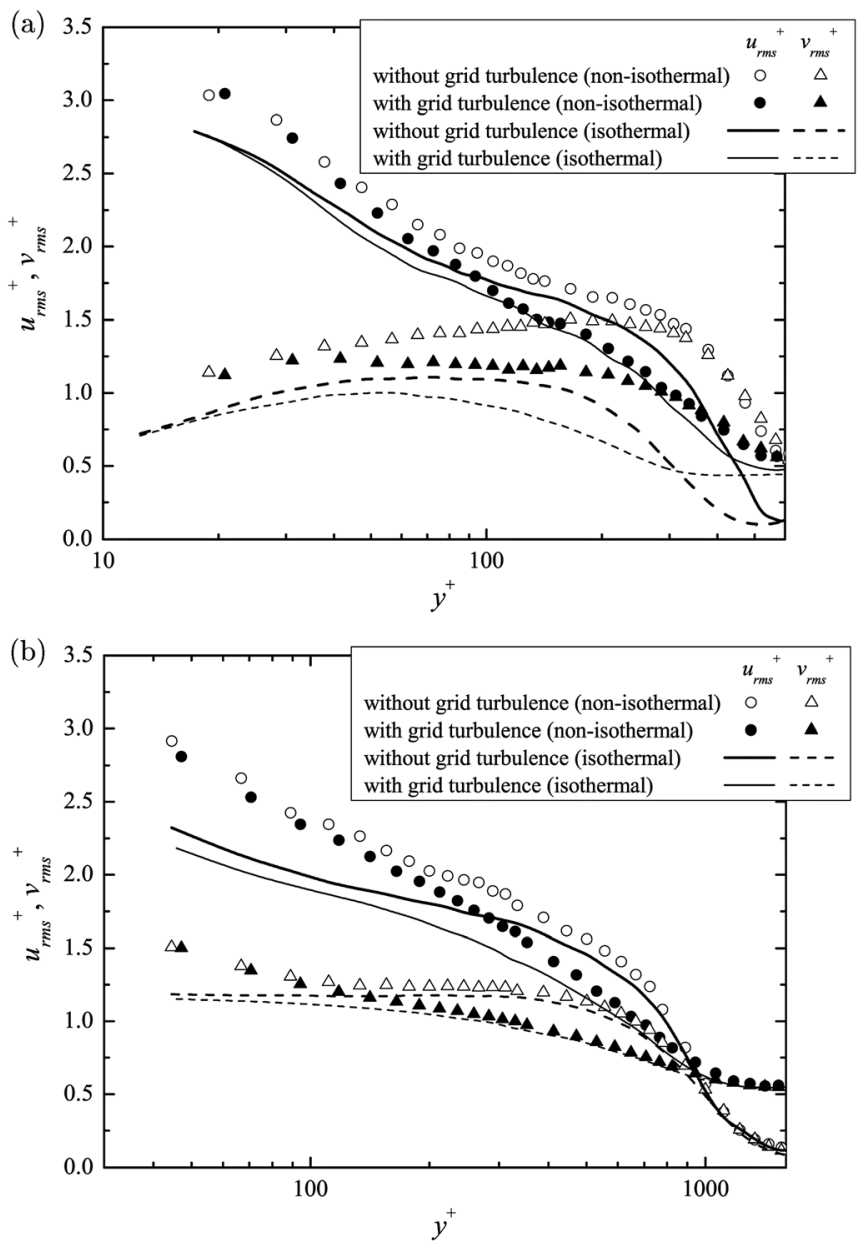

FIG. 16. Vertical distributions of rms velocities near the wall: (a) $R i_{b}=0.115$ and (b) $R i_{b}=1.35 \times 10^{-2}$.

stress. This result suggests that Reynolds' analogy for momentum and heat transfer holds since the wall friction increases under the effect of the freestream turbulence, as indicated by Simonich and Bradshaw ${ }^{26}$ for the forced convective case. The increase in Reynolds shear stress near the wall is more significant in the non-isothermal boundary layer

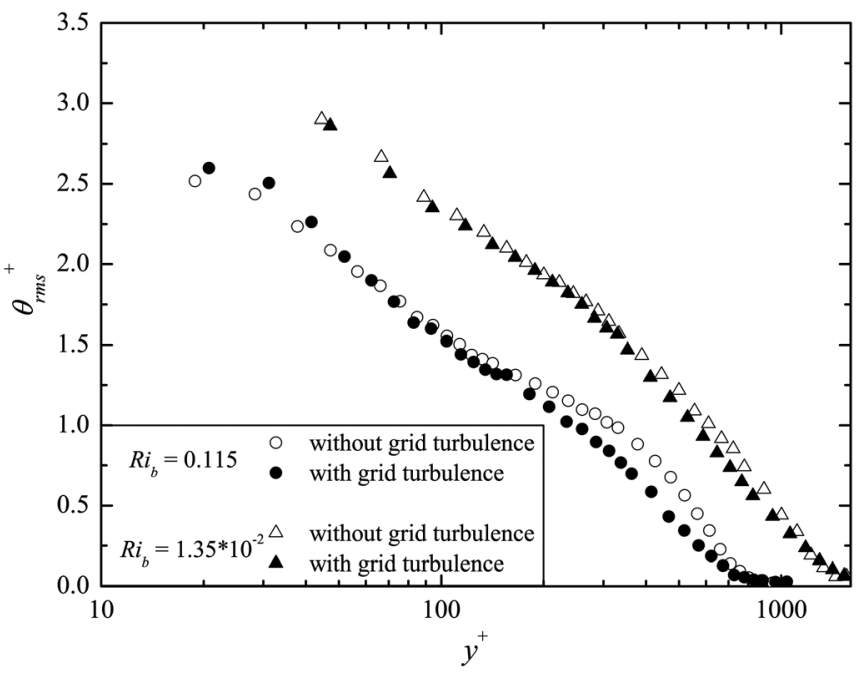

FIG. 17. Vertical distributions of rms temperature near the wall. 
(a)
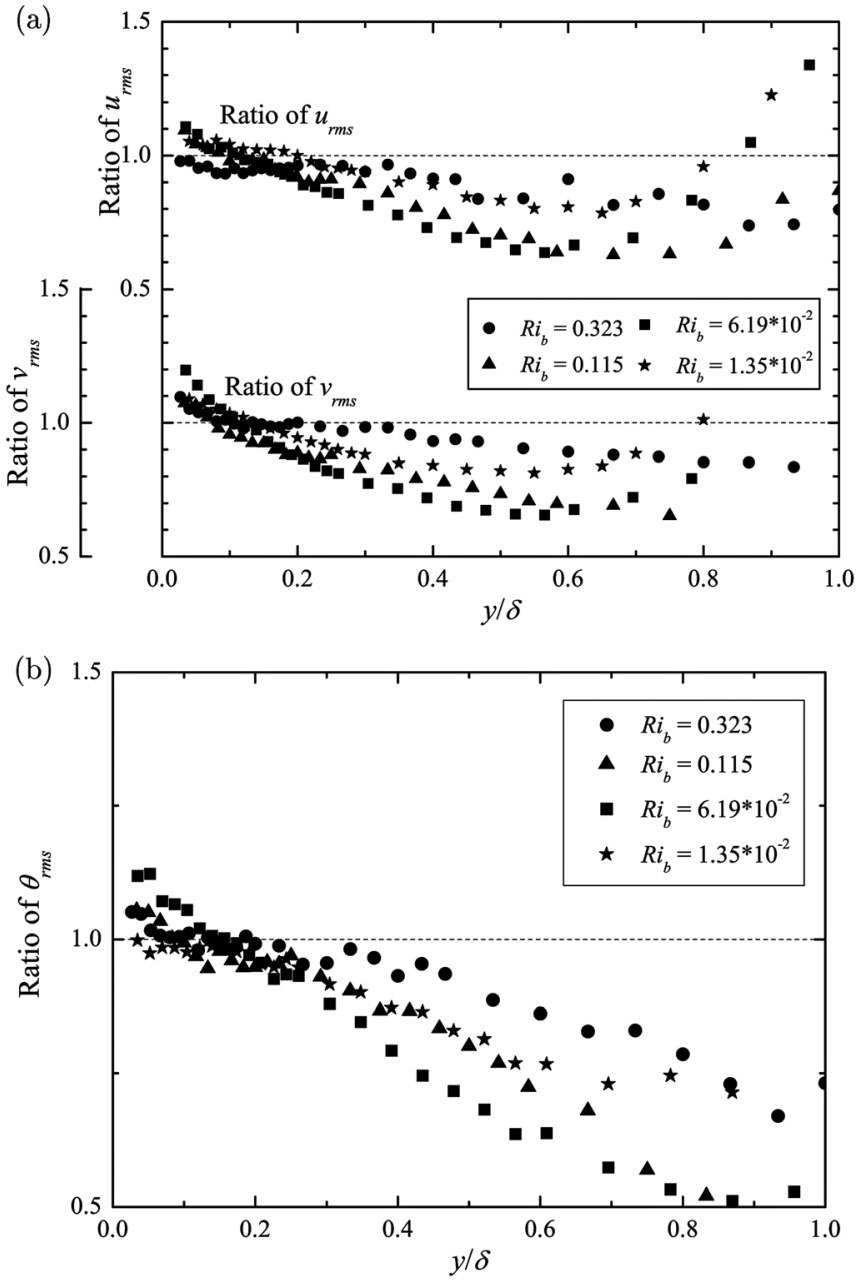

FIG. 18. Vertical distributions of the ratio of rms values with and without freestream turbulence: (a) ratio of rms velocities, $u_{r m s}$ (with FST) $/ u_{r m s}$ (without FST) and $v_{r m s}$ (with FST) $/ v_{r m s}$ (without FST) and (b) ratio of rms temperatures, $\theta_{r m s}$ (with FST) $/ \theta_{r m s}$ (without FST).

than in the isothermal boundary layer (Fig. 6): it is enhanced by approximately $40 \%$ in the non-isothermal boundary layer by the freestream, whereas it is enhanced by approximately

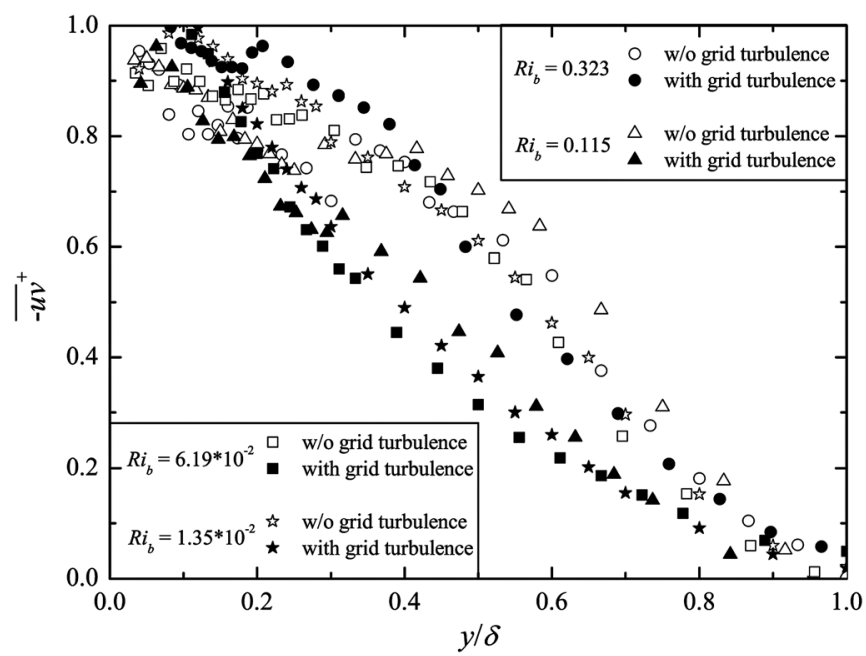

FIG. 19. Vertical distributions of the normalized Reynolds shear stress near the wall.

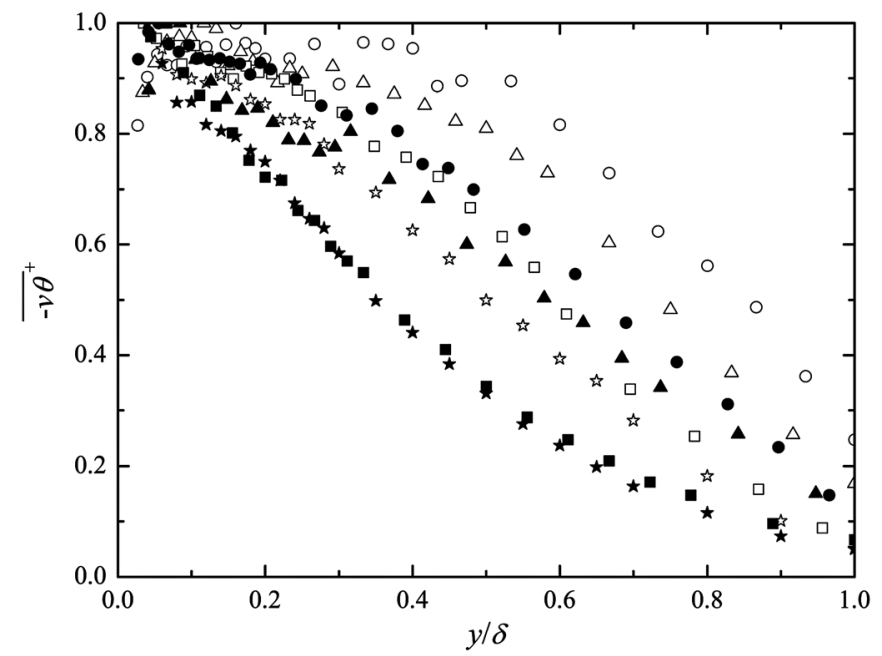

FIG. 20. Vertical distributions of the normalized vertical turbulent heat flux near the wall. Symbols as in Fig.19.

$20 \%$ in the isothermal case. Note that in the forced convective boundary layer, where buoyancy effects are negligible, Edwards and Furber, ${ }^{23}$ Büyüktür et al. ${ }^{24}$ and Kestin et al. ${ }^{46}$ observed no discernible effects of freestream turbulence on turbulent heat transfer at the wall. On the other hand, McDonald and Kreskovsky, ${ }^{25}$ Simonich and Bradshaw, ${ }^{26}$ and Blair ${ }^{4,21}$ found that the freestream turbulence caused an increase in heat transfer at the wall. Simonich and Bradshaw $^{26}$ suggested that at a sufficiently high Reynolds number, the heat transfer would be promoted by the freestream turbulence in a forced convective boundary layer. Our results for non-isothermal boundary layers with buoyancy effects are consistent with those of McDonald and Kreskovsky, ${ }^{25}$ Simonich and Bradshaw, ${ }^{26}$ and Blair ${ }^{4,21}$ for forced convective boundary layers in the absence of buoyancy effects, although our Reynolds number is not large. On the other hand, away from the wall, the reductions in Reynolds shear stress and vertical turbulent heat flux are significant in the moderate stratification at $R i_{b}=6.19 \times 10^{-2}$, as for the rms velocities and rms temperature.

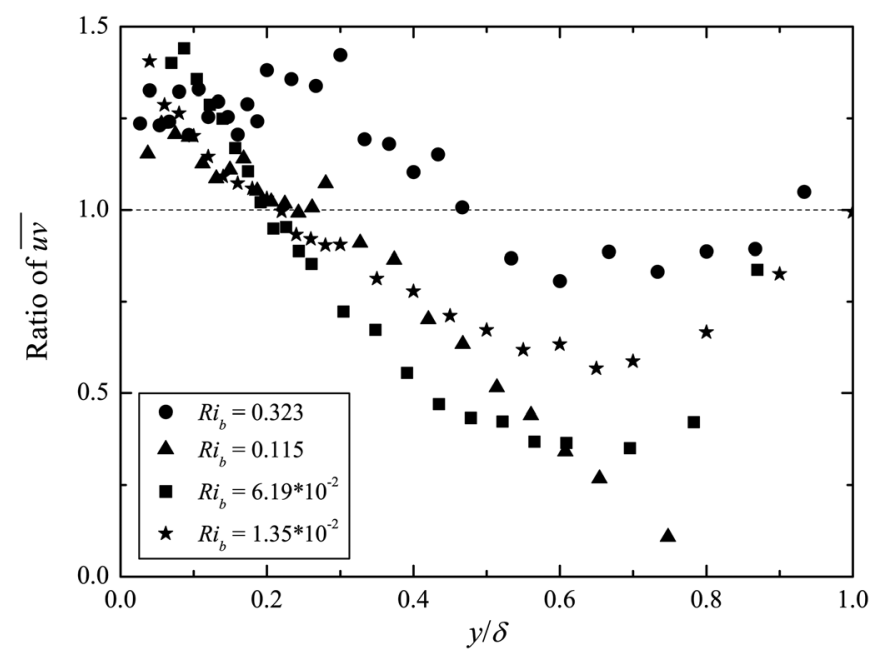

FIG. 21. Vertical distributions of the ratio of Reynolds shear stress with and without freestream turbulence, $\overline{u v}$ (with FST)/ $/ \overline{u v}$ (without FST). 


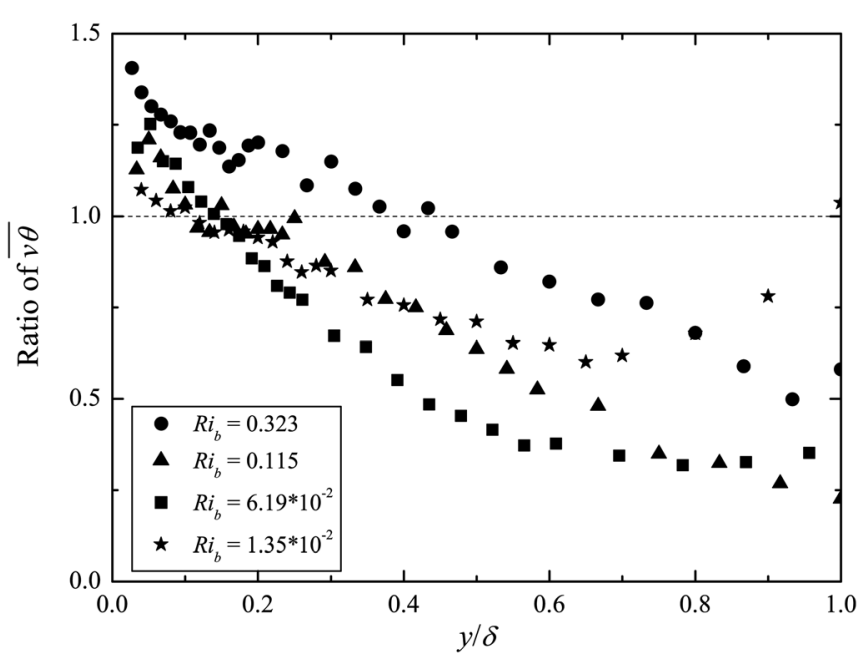

FIG. 22. Vertical distributions of the ratio of vertical heat flux with and without freestream turbulence, $\overline{v \theta}$ (with FST) $\overline{v \theta}$ (without FST).

(a)

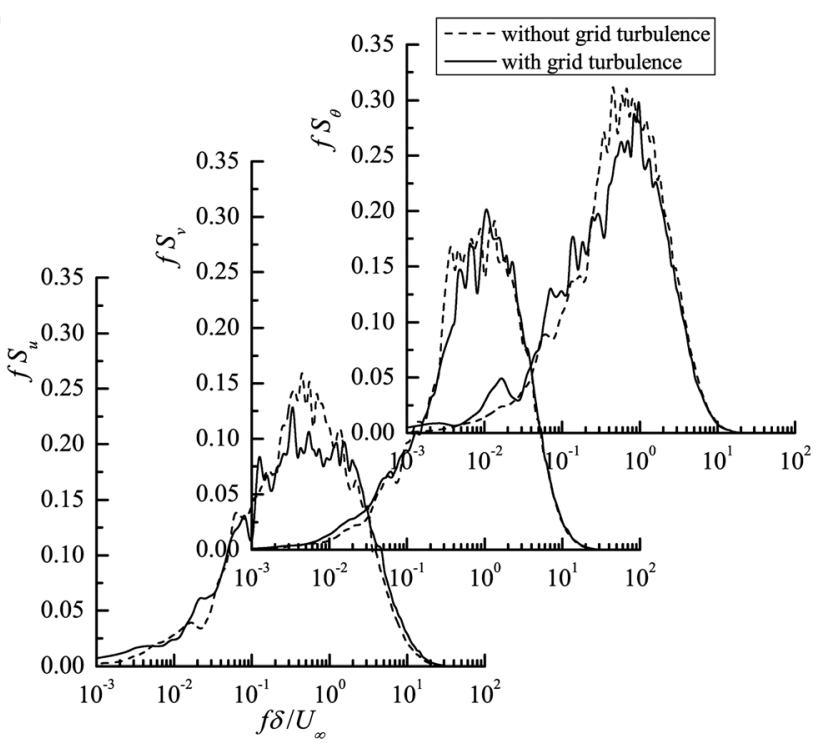

(b)

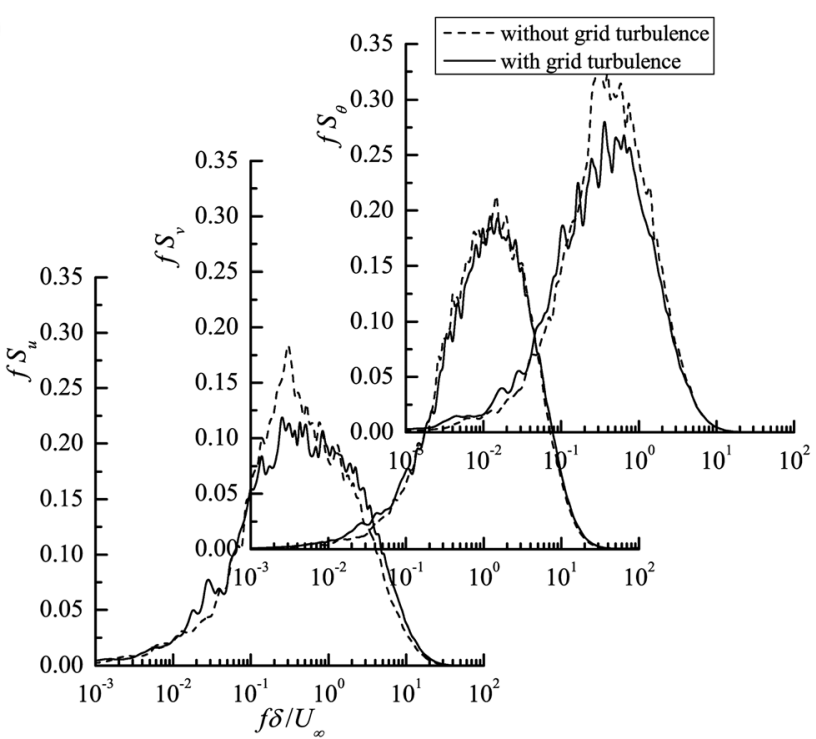

FIG. 23. Premultiplied power spectra of $u$, $v$, and $\theta$ : (a) $R i_{b}=0.115$ and (b) $R i_{b}=1.35 \times 10^{-2}$.
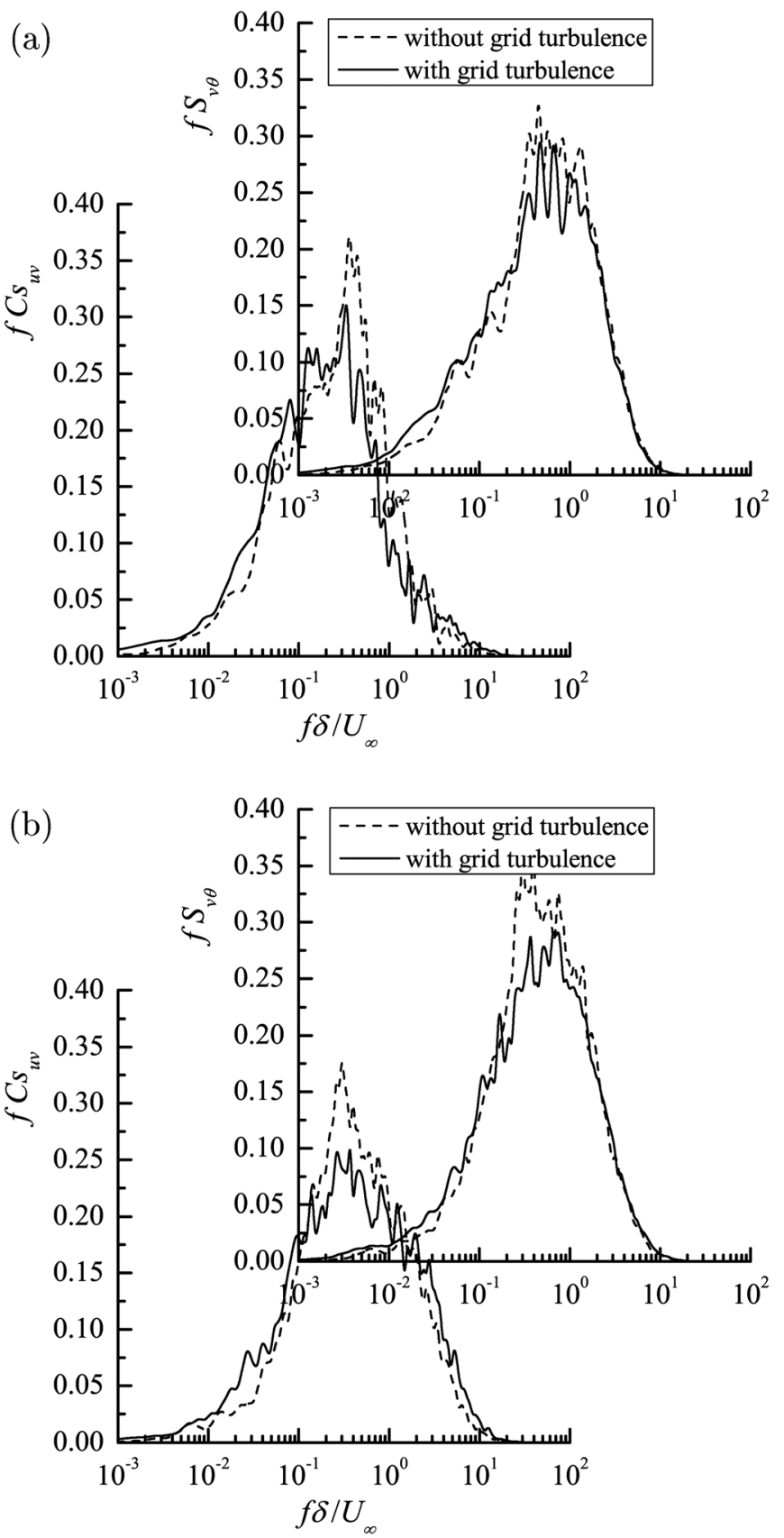

FIG. 24. Premultiplied cospectra of $\overline{u v}$ and $\overline{v \theta}$ : (a) $R i_{b}=0.115$ and (b) $R i_{b}=1.35 \times 10^{-2}$.

Figures 23 and 24 show the premultiplied power spectra of $u, v$, and $\theta$ and the cospectra of $-\overline{u v}$ and $\overline{v \theta}$, respectively. The measuring point is $y=0.05 \mathrm{~m}$, which corresponds to $y^{+} \sim 250$ and $y / \delta \sim 0.42$ for $R i_{b}=0.115$ and to $y^{+} \sim 580$ and $y / \delta \sim 0.50$ for $R i_{b}=1.35 \times 10^{-2}$. The cospectrum of $\overline{v \theta}$ is defined as

$$
\overline{v \theta}=\int_{0}^{\infty} C s_{v \theta}(f) d f .
$$

Here, the cospectra are normalized by the Reynolds shear stress or vertical heat flux. Although we observe a slight decrease in the peak value of the cospectra $C s_{u v}$ and $C s_{v \theta}$, the overall features of the cospectra are not significantly altered by the freestream turbulence. Thus, the turbulence 


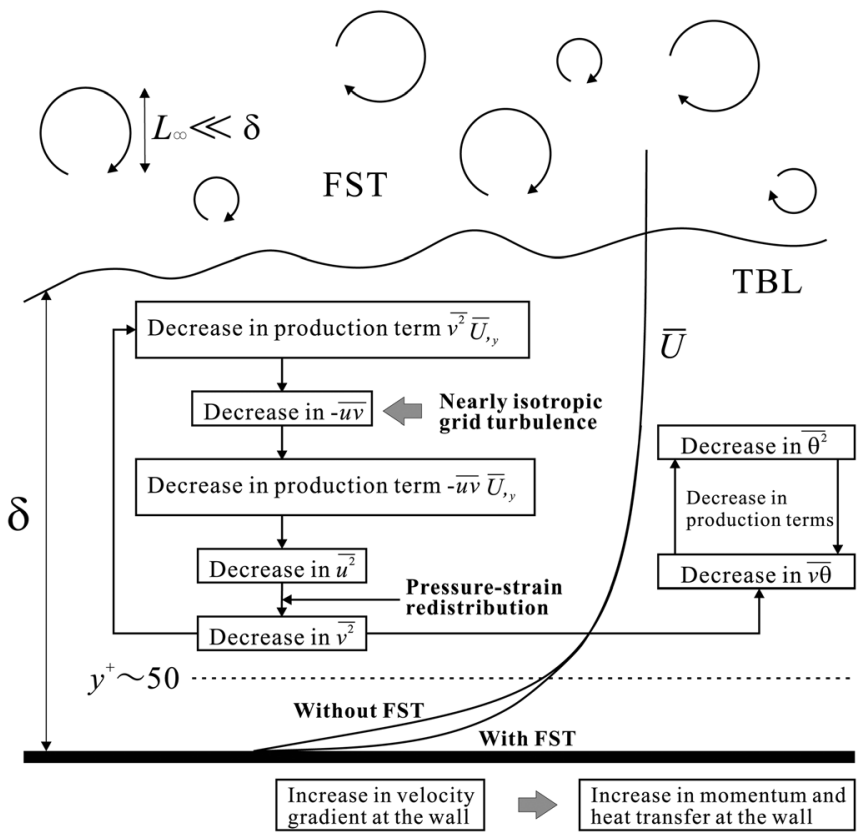

FIG. 25. Illustration showing the possible effect of FST on TBL with heat transfer under the condition $L_{\infty} / \delta \ll 1$ and low $T_{u}$.

structures in a boundary layer with a strong buoyancy force do not vary significantly with the freestream turbulence, and motions of almost all scales are suppressed without destroying the original eddy structures, just as in the present isothermal boundary layers (see Figs. 9 and 12).

Finally, Fig. 25 illustrates the possible effect of freestream turbulence, deduced from this study, on a turbulent boundary layer with heat transfer when $L_{\infty} / \delta \ll 1$ and $T_{u}$ is not large $(\sim 3 \%)$. Since the freestream turbulence is nearly isotropic, it may reduce the Reynolds shear stress in a turbulent boundary layer, as suggested by Charnay et al. ${ }^{14}$ Note that this effect could apply even for $L_{\infty} / \delta>1$, as shown by Sharp et $a l .{ }^{41}$ Then, the streamwise turbulence intensity decreases because of the reduction in the production term

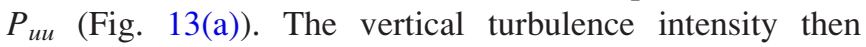
decreases through the pressure-strain redistribution. Note that when $\delta \ll L_{\infty}$ or $u_{\infty}^{\prime}$ in a freestream flow is intense compared with the turbulence in a turbulent boundary layer, turbulent intensities in the turbulent boundary layer will simply be enhanced by the stirring and/or blocking effect of the freestream turbulence, as shown in Hancock and Bradshaw. ${ }^{17}$ When the vertical turbulence intensity decreases, the Reynolds shear stress decreases because of the reduction in the production term $P_{u v}$ (Fig. 13(b)). These processes are strongly interrelated. In a non-isothermal boundary layer, the vertical turbulent heat flux decreases because $v$ decreases, or more precisely, because the production term for $\overline{v \theta}$, $-\overline{v^{2}}(\partial \bar{T} / \partial y)$ decreases. Then, the temperature fluctuation decreases because the production term for $\overline{\theta^{2}},-2 \overline{v \theta}(\partial \bar{T} / \partial y)$ decreases. These processes are also mutually related. On the other hand, in the vicinity of the wall, the vertical velocity gradient increases when the freestream is turbulent, as many experimental data have shown (for the isothermal case). ${ }^{14-19}$ This causes an increase in $-\overline{u v}$ and $\overline{v \theta}$ in the vicinity of the wall. The buoyancy only affects the magnitude of the modifi- cation caused by the freestream turbulence. It would be interesting to investigate how turbulence quantities such as rms values and momentum and heat fluxes change under stably stratified conditions to verify these possible mechanisms.

\section{CONCLUSIONS}

The effects of freestream grid turbulence on isothermal and non-isothermal turbulent boundary layers with a strong buoyancy force are investigated using a wind tunnel under the condition $L_{\infty} / \delta \ll 1$ and $T_{u}=1.3 \% \sim 2.4 \%$. The main results from this study can be summarized as follows:

1. The rms velocities and Reynolds shear stress normalized by the wall parameters are strongly suppressed by the freestream turbulence in isothermal and non-isothermal boundary layers. In non-isothermal boundary layers, the rms temperature and vertical turbulent heat flux normalized by the wall parameters are also suppressed by the freestream turbulence. The power spectra and cospectra suggested that the turbulence structures in the isothermal and non-isothermal boundary layers do not vary significantly with the freestream turbulence, and motions of almost all scales are suppressed. In the vicinity of the wall (typically $y^{+}<50$ ), turbulence quantities normalized by the wall parameter are not affected by the freestream turbulence.

2. The effects of freestream turbulence on non-isothermal boundary layers with buoyancy effect are not straightforward: they depend on the buoyancy effect. At $R i_{b},=0.323$, the effects of freestream turbulence are weaker than those in the isothermal case because of the energetic convective motions. The effects of freestream turbulence are most significant in moderate stratification at $R i_{b}=6.19 \times 10^{-2}$. At the higher Reynolds number (or smaller $R i_{b}$ ) at $R i_{b}=1.35 \times 10^{-2}$, in which the buoyancy force is weak and the mean velocity profile is similar to the isothermal case, the effects of the freestream turbulence become less significant again.

3. Freestream turbulence enhances skin friction and heat transfer at the wall. The effect is more significant in unstable stratification.

\section{ACKNOWLEDGMENTS}

The authors would like to thank Mr. Akihito Ito (Kyoto University) and Dr. Hiroki Suzuki (Nagoya University) for their help in this study. The authors also acknowledge valuable comments by the anonymous referees and by Professor J. C. R. Hunt (University College London) and Professor J. C. Vassilicos (Imperial College London). This study was partially supported by the Japanese Ministry of Education, Culture, Sports, Science, and Technology through Grant-in-Aid (Nos.18686015, 22360076, and 22360077).

${ }^{1}$ U. L. F. Högström, J. C. R. Hunt, and A.-S. Smedman, "Theory and measurements for turbulence spectra and variances in the atmospheric neutral surface layer," Boundary-Layer Meteorol. 103, 101 (2002).

${ }^{2}$ H. McDonald and R. W. Fish, "Practical calculations of transitional boundary layers," Int. J. Heat Mass Transfer 16, 1729 (1973).

${ }^{3}$ J. A. Hoffmann, "Effects of free-stream turbulence on diffuser performance," ASME Trans. J. Fluids Eng. 103, 385 (1981). 
${ }^{4}$ M. F. Blair, "Influence of free-stream turbulence on turbulent boundary layer heat transfer and mean profile development. Part 1. Experimental data," ASME Trans. J. Heat Transfer 105, 33 (1983).

${ }^{5}$ P. R. Voke and Z. Yang, "Numerical study of bypass transition," Phys. Fluids 7(9), 2256 (1995).

${ }^{6} \mathrm{M}$. Kalter and H. H. Fernholz, "The reduction and elimination of a closed separation region by free-stream turbulence," J. Fluid Mech. 446, 271 (2001).

${ }^{7}$ D. M. Driver, "Reynolds shear stress measurements in a separated boundary layer flow," AIAA Pap. 91-1787, 1 (1991).

${ }^{8}$ A. E. Alving and H. H. Fernholz, "Turbulence measurements around a mild separation bubble and downstream of reattachment," J. Fluid Mech. 322, 297 (1996).

${ }^{9}$ R. Hillier and N. J. Cherry, "The effects of stream turbulence on separation bubbles," J. Wind Eng. Ind. Aerodyn. 8, 49 (1981).

${ }^{10}$ Y. Nakamura and S. Ozono, "The effects of turbulence on a separated and reattaching flow,” J. Fluid Mech. 178, 477 (1987).

${ }^{11}$ I. P. Castro and A. Haque, "The structure of a shear layer bounding a separation region. Part 2. Effects of free-stream turbulence," J. Fluid Mech. 192, 577 (1988).

${ }^{12} \mathrm{~K}$. Isomoto and S. Honami, "The effect of inlet turbulence intensity on the reattachment process over a backward-facing step,” ASME Trans. J. Fluids Eng. 111, 87 (1989).

${ }^{13}$ N. K. Pui and I. S. Gartshore, "Measurements of the growth rate and structure in plane turbulent mixing layers," J. Fluid Mech. 91, 111 (1979).

${ }^{14} \mathrm{G}$. Charnay, G. Comte-Bellot, and J. Mathieu, "Development of a turbulent boundary layer on a flat plate in an external turbulent flow," AGARD Conf. Proc. 93(27), 1 (1971).

${ }^{15}$ R. L. Evans, "Free-stream turbulence effects on the turbulent boundary layer," ARC CP, No. 1282 (1973).

${ }^{16}$ P. E. Hancock and P. Bradshaw, "The effect of free-stream turbulence on turbulent boundary layers,” ASME Trans. J. Fluids Eng. 105, 284 (1983).

${ }^{17}$ P. E. Hancock and P. Bradshaw, "Turbulence structure of a boundary layer beneath a turbulent free stream," J. Fluid Mech. 205, 45 (1989).

${ }^{18}$ I. P. Castro, "Effects of free stream turbulence on low Reynolds number boundary layers,” ASME Trans. J. Fluids Eng. 106, 298 (1984).

${ }^{19}$ G. D. Huffman, D. R. Zimmerman, and W. A. Bennett, "The effect of free-stream turbulence level on turbulent boundary layer behaviour," AGARD AG 164, 91 (1972).

${ }^{20}$ H. U. Meier and H.-P. Kreplin, "Influence of freestream turbulence on boundary-layer development," AIAA J. 18(1), 11 (1980).

${ }^{21}$ M. F. Blair, "Influence of free-stream turbulence on turbulent boundary layer heat transfer and mean profile development. Part 2-Analysis of the results," ASME Trans. J. Heat Transfer 105, 41 (1983).

${ }^{22}$ S. J. Kline, A. V. Lisin, and B. A. Waitman, "Preliminary experimental investigation of effect of free-stream turbulence on turbulent boundarylayer growth," NASA TN D-368, 1 (1960).

${ }^{23} \mathrm{~A}$. Edwards and B. N. Furber, "The influence of free-stream turbulence on heat transfer by convection from an isolated region of a plane surface in parallel air flow," Proc. Inst. Mech. Eng. 170(28), 941 (1956).

${ }^{24}$ A. R. Büyüktür, J. Kestin, and P. F. Maeder, "Influence of combined pressure gradient and turbulence on the transfer of heat from a plate," Int. J. Heat Mass Transfer 7, 1175 (1964).
${ }^{25} \mathrm{H}$. McDonald and J. P. Kreskovsky, "Effect of free stream turbulence on the turbulent boundary layer," Int. J. Heat Mass Transfer 17, 705 (1974).

${ }^{26}$ J. C. Simonich and P. Bradshaw, "Effect of free-stream turbulence on heat transfer through a turbulent boundary layer," ASME Trans. J. Heat Transfer 100, 671 (1978).

${ }^{27}$ R. Kurose, H. Makino, and S. Komori, "Particle trajectory in turbulent boundary layer at high particle Reynolds number," ASME Trans. J. Fluids Eng. 123, 956 (2001).

${ }^{28}$ G. Comte-Bellot and S. Corrsin, "Simple Eulerian time correlation of fulland narrow-band velocity signals in grid-generated 'isotropic' turbulence," J. Fluid Mech. 48(2), 273 (1971).

${ }^{29}$ I. Nakamura, Y. Sakai, and M. Miyata, "Diffusion of matter by a non-buoyant plume in grid-generated turbulence," J. Fluid Mech. 178, 379 (1987).

${ }^{30}$ Jayesh, K. Yoon, and Z. Warhaft, "Turbulent mixing and transport in a thermally stratified interfacial layer in decaying grid turbulence," Phys. Fluids A 3(5), 1143 (1991).

${ }^{31}$ J. H. Lienhard V and C. W. Van Atta, "The decay of turbulence in thermally stratified flow," J. Fluid Mech. 210, 57 (1990).

${ }^{32}$ S. T. Thoroddsen and C. W. Van Atta, "The effects of a vertical contraction on turbulence dynamics in a stably stratified fluid," J. Fluid Mech. 285, 371 (1995).

${ }^{33} \mathrm{~K}$. Bremhorst and S. M. Anderson, "Effect of cold wire inclination on temperature fluctuation measurements in a heated jet," Exp. Therm. Fluid Sci. 27, 199 (2003).

${ }^{34}$ A. E. Perry, Hot Wire Anemometry (Oxford University Press, New York, 1982).

${ }^{35}$ J. O. Hinze, Turbulence (McGraw-Hill, New York, 1959).

${ }^{36} \mathrm{~W}$. H. Snyder and I. P. Castro, "The yaw response of hot-wire probes at ultra-low wind speeds,” Meas. Sci. Technol. 9, 1531 (1998).

${ }^{37}$ D. B. DeGraaff and J. K. Eaton, "Reynolds-number scaling of the flat-plate turbulent boundary layer," J. Fluid Mech. 422, 319 (2000).

${ }^{38} \mathrm{P}$. R. Spalart, "Direct simulation of a turbulent boundary layer up to $R_{\theta}=1410$," J. Fluid Mech. 187, 61 (1988).

${ }^{39}$ J. H. Lee and H. J. Sung, "Direct numerical simulation of a turbulent boundary layer up to $R_{\theta}=2500$," Int. J. Heat Fluid Flow 32, 1 (2011).

${ }^{40} \mathrm{~K}$. A. Thole and D. G. Bogard, "High freestream turbulence effects on turbulent boundary layers," ASME Trans. J. Fluids Eng. 118, 276 (1996).

${ }^{41}$ N. S. Sharp, S. Neuscamman, and Z. Warhaft, "Effects of large-scale free stream turbulence on a turbulent boundary layer," Phys. Fluids 21, 095105 (2009).

${ }^{42}$ J. C. R. Hunt and J. M. R. Graham, "Free-stream turbulence near plane boundaries,” J. Fluid Mech. 84, 209 (1978).

${ }^{43}$ K. Nagata, H. Wong, J. C. R. Hunt, S. G. Sajjadi, and P. A. Davidson, "Weak mean flows induced by anisotropic turbulence impinging onto planar and undulating surfaces," J. Fluid Mech. 556, 329 (2006).

${ }^{44}$ I. P. Castro and E. Epik, "Boundary layer development after a separated region," J. Fluid Mech. 374, 91 (1998).

${ }^{45} \mathrm{H}$. Hattori, T. Houra, and Y. Nagano, "Direct numerical simulation of stable and unstable turbulent thermal boundary layers," Int. J. Heat Fluid Flow 28, 1262 (2007).

${ }^{46}$ J. Kestin, P. F. Maeder, and H. E. Wang, "Influence of turbulence on the transfer of heat from plates with and without a pressure gradient," Int. J. Heat Mass Transfer 3, 133 (1961). 